Old Dominion University

ODU Digital Commons

Winter 1993

\title{
Instability Waves in the Gulf Stream Front and Its Thermocline Layer
}

Sang-Ki Lee

Old Dominion University

Follow this and additional works at: https://digitalcommons.odu.edu/oeas_etds

Part of the Oceanography Commons

\section{Recommended Citation}

Lee, Sang-Ki. "Instability Waves in the Gulf Stream Front and Its Thermocline Layer" (1993). Master of Science (MS), Thesis, Ocean \& Earth Sciences, Old Dominion University, DOI: 10.25777/ksdc-bt05 https://digitalcommons.odu.edu/oeas_etds/102

This Thesis is brought to you for free and open access by the Ocean \& Earth Sciences at ODU Digital Commons. It has been accepted for inclusion in OES Theses and Dissertations by an authorized administrator of ODU Digital Commons. For more information, please contact digitalcommons@odu.edu. 


\title{
INSTABILITY WAVES IN THE GULF STREAM FRONT AND ITS THERMOCLINE LAYER.
}

\author{
by \\ Sang-Ki Lee \\ Bachelor of Science, February 1991 \\ Inha University, Incheon, Republic of Korea \\ A Thesis submitted to the Faculty of
}

Old Dominion University in Partial Fulfillment of the

Requirement for the Degree of

\section{MASTER OF SCIENCE \\ OCEANOGRAPHY}

\section{OLD DOMINION UNIVERSITY \\ DECEMBER, 1993}

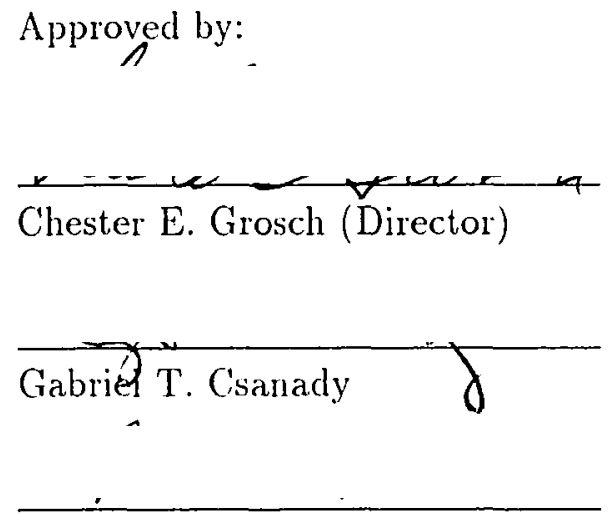

A. D. Kirwan, Jr.

Johin A. Adam 


\title{
Abstract \\ INSTABILITY WAVES IN THE GULF STREAM FRONT AND ITS THERMOCLINE LAYER.
}

\author{
Sang-Ki Lee \\ Old Dominion University, 1993 \\ Director: Prof. Chester E. Grosch
}

Linear instability calculations were carried out on a three layer Gulf Stream front model in an attempt to elucidate the interaction of the thermocline layer with surface slopewater shoreward of the front. The basic state is geostrophic balance and constant potential vorticity in the two active layers, but the perturbations are ageostrophic. The flow is found to be unstable to long wave perturbations, the wavelength of the most unstable wave to be of order 10 radii of deformation. The instability is mainly baroclinic, $75-85 \%$ of the energy supply to the growing perturbation coming from basic flow potential energy. Calculated wavelengths and growth rates, using parameters typical of the Gulf Stream, are similar to those observed. The eigenfunctions and particle trajectories reveal large cross-frontal excursions in the thermocline layer, and a large, if weak, cyclonic eddy in the surface slopewater in a meander trough. 
To my parents

Reproduced with permission of the copyright owner. Further reproduction prohibited without permission. 


\section{Acknowledgements}

I wish to thank my advisor, Dr. Chet Grosch, for his guidance and support. My thanks also goes to the other members of my committee, Dr. Gabe Csanady, Dr. Albert Kirwan, Jr. and Dr. John Adam. Particularly, I express my deep gratitude to Dr. Gabe Csanady. His guidance with patience and encouragement during the last two years was most invaluable. I would also like to take the opportunity to thank Dr. John Klinck, Dr. Larry Atkinson and Dr. William Dunstan for their support and kindness.

I am deeply grateful to Dr. Jose Pelegri, Dr. Han-Jun Woo, Dr. Glen Wheless, Dr. Dong-Beom Kim, Kyung-Soo Park and Young-Teag Kim for their encouragement and helpful advice throughout the years. Friendships from Vittal Gudavalli, Ana Martins, Andry Ratsimadresy, Dr. Andras Kapolnai, Dolisa Hommel, Ajoy Kumar, Yvette Spitz, Sunny Wu and Marge Dekshenieks have given me the strength to pursue this degree. I should not forget to thank my fellow students in the oceanography department, Xia Weiping, Ajcharaporn Udomkit and Hu Lin who always welcomed me in the other side of the department. I am obliged to the staff of the Oceanography department, Billie Fedyszyn, Dana Oblak, Faye Carrington and Karen Calogrides, and especially to the staff at CCPO, Carole Hannah, Dr. Wayne Schroll, Beverly Mitchels, Karal Gregoiry and Julie Rea for their continous help. I am also indebted to my fellow Korean graduate students in ODU and their families. Their help was crucial during the pursuit of this degree.

I would like to thank Prof. Young-Ho Seung for his encouragement, and my fellows in Inha University, Kuk-Jin Kim, Sang-Ik Shin, Ho-Suk Kang, Chi-Gwan 
Lee, Eun-Jin Yang and Won-Sun Park for the friendship. I offer my gratitude to the oceanography department and the CCPO for the financial support. Computer resources and facilities were provided by the Commonwealth Center for Coastal Physical Oceanography.

Finally, I would like to thank my father, mother and my brother for their unconditional love and support. 


\section{Contents}

List of Figures $\quad$ ix

1 Introduction 1

2 Formulation of the Problem 6

3 The Basic Flow $\quad 11$

4 The Perturbation Equations 14

5 The Isolated Front $\quad 16$

5.1 Boundary Conditions . . . . . . . . . . . . . . 16

5.2 Eigenvalue Problem . . . . . . . . . . . . . . . 18

6 The Coastal Front $\quad 21$

6.1 Boundary Conditions . . . . . . . . . . . . . . 21

6.2 Eigenvalue Problem . . . . . . . . . . . . . 22

7 Calculated Results 23

7.1 Isolated Front . . . . . . . . . . . . . . . . 23 
7.2 Coastal Front, Flat Bottom . . . . . . . . . . . 31

7.3 Coastal Front, Sloping Bottom . . . . . . . . . . . . 34

8 Particle Motions in Unstable Wave Fields $\quad 47$

9 Energy Considerations $\quad 50$

9.1 Wave Energy Equations .................... 50

9.2 Application to the Isolated Front. . . . . . . . . . . . 52

9.3 Application to the Coastal Front ... . . . . . . . . . 52

10 Conclusions $\quad 57$

$\begin{array}{lr}\text { Appendix } & 59\end{array}$

$\begin{array}{lr}\text { Bibliography } & 61\end{array}$ 


\section{List of Figures}

1 The configuration for the three-layer model: (a) isolated front, (b) coastal front. .................... 7

2 Basic geostrophic flow of the isolated front: (a) Layer thickness, (b) Velocity when $\alpha=1, \delta=1$ and $\gamma=8 \ldots \ldots \ldots 13$

3 Isolated front: (a) Frequency of the fastest growing wave as a function of along front wave number $\kappa$, (b) Growth rate of the fastest growing wave as a function of along front wave number $\kappa . \ldots \ldots$

4 Isolated front: Eigenfunctions of the most unstable wave of (a) the top layer, (b) the thermocline layer and (c) the bottom layer. . . . . . . 26

5 Isolated Front: Two-dimensional structure of the eigenfunctions (contours of pressure and velocity vectors), (a) the top layer: contours from -1.28 to $1.07, \mathrm{CI}=0.21$, $\max$ vector $=0.42$; (b) the thermocline layer: contours from -0.30 to $0.25, \mathrm{CI}=0.05$, $\max$ vector $=0.24 ;(\mathrm{c})$ the bottom layer: contours from -0.11 to $0.09, \mathrm{CI}=0.02$, $\max$ vector $=0.05$, wavy line indicates the phase of the surface front displacement. . . .

6 Growth rate of the fastest growing wave as a function of along front wave number $\kappa$, for $\gamma=4,6,8$ : Isolated front. . . . . . . . . 32

7 Coastal front, flat bottom: (a) Frequency of the fastest growing wave as a function of along front wave number $r$, (b) Growth rate of the fastest growing wave as a function of along front wave number $\kappa$. . .

8 Hyperbolic tangential shape of bottom topography for $H_{0}=3$ along with the basic geostrophic frontal structure. . . . . . . . . . 36 
9 Coastal front, sloping bottom: (a) Frequency of the fastest growing wave as a function of along front wave number $\kappa$, (b) Growth rate of the fastest growing wave as a function of along front wave number $\kappa$.

10 Coastal front, sloping bottom: Eigenfunctions of the most unstable wave of (a) the top layer, (b) the thermocline layer and (c) the bottom layer. . . . . . . . . . . . . . . . .

11 Coastal front, sloping bottom: Two-dimensional structure of the eigenfunctions (contour of pressure and velocity vector), (a) the top layer: contour from -1.26 to $1.05, \mathrm{CI}=0.21$, $\max$ vector $=0.58$; $(\mathrm{b})$ the thermocline layer: contour from -0.31 to $0.26, \mathrm{CI}=0.05, \max$ vector $=0.29$; (c) the bottom layer: contour from -0.03 to $0.03, \mathrm{CI}=0.004$, $\max$ vector $=0.02$, wavy line indicates the phase of the surface front displacement. 40

12 Growth rate of the fastest growing wave as a function of along front wave number $\kappa$, for $H_{0}=2,3$ and $4 \ldots \ldots \ldots 43$

13 Coastal front, sloping bottom: A time series of total flow in the thermocline layer for one period: (a) $\mathrm{T}=1 / 4$ period, $\mathrm{CI}=0.14$, $\max$ vector $=0.3 ;$ (b) $\mathrm{T}=2 / 4$ period, $\mathrm{CI}=0.14, \max$ vector $=0.34 ;$ (c) $\mathrm{T}=3 / 4$ period, $\mathrm{CI}=0.14, \max$ vector $=0.50$, dashed lines show the evolution of perturbed front $y_{f} \ldots \ldots \ldots \ldots . \ldots \ldots \ldots$

14 Trajectories of particles in the thermocline layer initially located at the point 'S'. An 'E' sign indicates the ending point. A ' + ' sign is placed at each time step. . . . . . . . . . . . . . .

15 Isolated front: (a) Energy conversion rate term $C\left(K_{m} \rightarrow K_{u}^{\prime}\right)$, (b) Energy conversion rate term $C\left(P_{m} \rightarrow P_{w}\right) \ldots \ldots . \ldots 5$ 
16 Coastal front, flat bottom: (a) Energy conversion rate term $C\left(K_{m l} \rightarrow\right.$ $\left.K_{w}\right)$, (b) Energy conversion rate term $C\left(P_{m} \rightarrow P_{w}\right) \ldots \ldots 54$

17 Coastal front, sloping bottom: (a) Energy conversion rate term $C\left(K_{m} \rightarrow\right.$ $\left.K_{w}\right)$, (b) Energy conversion rate term $C\left(P_{m} \rightarrow P_{w}\right) \ldots \ldots 55$ 


\section{Introduction}

Upon separation from the coast, western boundary currents develop unstable waves of spectacular amplitude, affecting a large neighboring region. In the case of the Gulf Stream, the affected region includes the Slope Sea, a $100 \mathrm{~km}$ or so wide strip of the ocean between the stream and the continental slope. A remarkable fact reported by Bane et al [1988] is that when a Gulf Stream meander approaches the continental shelf, squeezing the Slope Sea as it were, the southward flow of the upper slope current in the Mid-Atlantic Bight (MAB) speeds up. The upper slope current, is thought to be a leg of the western Slope Sea cyclonic gyre [Csanady and Hamilton, 1988], so that the squeezing of the gyre appears to speed it up. Another possibility is that shoreward motion by the Gulf Stream's surface layer is accompanied by offshore motion in the thermocline layer in contact with surface waters of the Slope Sea. In that case, the Gulf Stream thermocline exerts "suction" on the Slope Sea, a remote effect of which is the speeding up of the upper slope current. Whatever the exact explanation, there is clearly a connection between the movements of Gulf Stream's thermocline waters and Slope Sea waters, associated with the unstable waves of the boundary current. Here, a simple model of a separated boundary current is examined, to see how instability of flow affects waters in contact with the thermocline layer.

The instability of the Gulf Stream front is an important feature of both the global ocean circulation and the biochemical process in the MAB [Csanady, 1989)]. As a western boundary current, the Gulf Stream is the site where the main energy

dissipation of the Subtrophical Gyre takes place [Stommel, 1968]. Therefore, the 
instability of the Gulf Stream front is an important process for the global oceanic energy dissipations [Csanady, 1989].

At the same time, the cross-frontal exchange process, which maybe a result of frontal instabilities, is also a potentially important process influencing the biological activities in the frontal environment. Although the front serves a barrier preventing cross-frontal exchange of bio-chemical substances such as nutrients, nutrient fluxes can be initiated and enhanced in the cross-front direction due to the horizontal mixing produced during instabilities. Therefore, the high content of regenerated nutrients in the open ocean below the surface can be transported to the surface in the coastal area [Lee and Atkinson, 1983; Atkinson et al., 1987]. This may subsequently support higher trophical levels of the coastal environments [Paffenhofer et al., 1987; Lee et al,, 1991]. Several recent observational studies have found a strong correlation between the distributions of pigments, primary production and the Gulf Stream meandering [e.g. Hitchcock et al, 1993; Lohrenz et al, 1993].

Oceanic frontal instabilities have frequently been analyzed using quasi-geostrophic (QG hereafter) theory. However, the typical value of Rossby number for the Gulf Stream is order of one, and significant divergence may occur near the front, so that QG theory may be misleading [Garvine, 1983; Kubokawa, 1985; Barth, 1987; Kroll, 1992].

Theoretical studies of oceanic frontal instability originate from Orlanski's [1968] work. In his pioneering paper, Orlanski [1968] examined the instability of the (atmospheric) Norwegian polar front. He used a two-layer Margules front model intersecting rigid top and bottom boundaries as the steady basic state. Model results showed that the front was unstable at all wavelengths. Rayleigh shear instability, Kelvin-Helmholtz instability and baroclinic instability were all found to operate in some portion of wavenumber space. 
A second study by Orlanski [1969] analyzed a two-layer frontal model with cross stream variations of the bottom topography and geostrophic basic flows. The results showed that unstable waves obtained their energy mainly from the mean potential energy via baroclinic instability, while the influence of barotropic instability was insignificant and negative (with energy conversion from wave to mean kinetic energy: an example of negative viscosity effect [Starr, 1968]). His results agreed with observations made by Webster [1961] on the Gulf Stream in the South Atlantic Bight (SAB). Several, later observational studies on the Gulf Stream [Schmitz and Niiler, 1969; Brooks and Niiler, 1977] have confirmed Webster's results. Following Orlanski's work, a number of stability studies have been carried out on atmospheric and oceanic fronts. The trend of recent work has been away from QG theory, notable examples being the studies of Paldor [1983], Killworth [1983] and Killworth et al [1984] using the shallow water equations.

Paldor [1983] studied the instability of an "isolated" (upwelled) surface front using a simple reduced gravity model ( $1 \frac{1}{2}$ layer model $)$. His model consisted of an active top layer, overlying an infinitely deep bottom layer, of constant potential vorticity in the basic state. He found the model unconditionally stable, supporting trapped waves that could move either downstream or upstream. A slightly extended model was examined by Killworth [1983]. He allowed non-uniform potential vorticity in the simple $1 \frac{1}{2}$ layer model, and showed that the model front was unstable if the basic potential vorticity decreased toward the front. Interestingly, the criterion for instability found by Killworth [1983] is clearly different from what QG theory suggests, which is that the basic potential vorticity must change sign somewhere inside the fluid [Pedlosky, 1987], or in a two-layer QG model, the basic potential vorticity gradients in the two layers must have different signs [Phillips, 1954; Pedlosky, 1962; Orlanski, 1969]. 
The $1 \frac{1}{2}$ layer models include stratification in a highly simplified form, but eliminating perturbation in the bottom layer cannot portray baroclinic instability [Killworth, 1983; Barth, 1987]. An energy calculation by Kubokawa [1985] showed that energy conversion from mean to perturbation potential energy was not present in the $1 \frac{1}{2}$ layer model [see Fig. 7 in Kubokawa, 1985]. Furthermore, laboratory experiments [Chia et al, 1982; Griffiths and Linden, 1982], which all have active bottom layers, reveal frontal instability growth rates much larger than found by Killworth [1983]. Therefore, Killworth et al [1984] developed a two-layer model, allowing perturbations in the bottom layer, with basic flow in an active top layer and a stagnant bottom layer (a similar model was previously studied by Orlanski [1969]). Killworth et al [1984] obtained unstable waves regardless of the distribution of the basic potential vorticity. This model reproduced the growth rate of the most unstable wave in the laboratory experiments of Chia et al [1982] and Griffiths and Linden [1982]. The energy source for the instability was not clear, however.

Although Killworth et al [1984] were able to simulate the simplest mechanism of frontal instabilities, there are complications that arise in the case of the Gulf Stream front, such as the existence of an active thermocline layer which is in contact with surface waters of the Slope Sea. Therefore, the present study investigates, using a simplified three-layer model, the instability of the Gulf Stream front, in an attempt to understand the effect of an active thermocline layer, absent in a two-layer system. The energy exchange between the geostrophic basic flow and the perturbations is assessed, and cross-frontal unstable motions in the thermocline layer are portrayed in detail. Results are compared with those of Killworth et al [1984].

The thesis is organized in the following manner. The model is defined in chapter 2. In chapter 3 , the basic flow is described and briefly discussed. The perturbation equations are derived in chapter 4 . The boundary conditions and integration 
methods are presented for the isolated front in chapter 5 , and for the coastal front in chapter 6. Chapter 7 presents the solutions (eigenvalues and eigenfunctions) of the equations derived in chapter 4. Pathways of particles are calculated in chapter 8 . In chapter 9 , the energy transformation mechanism is discussed. Finally, the results are summarized and conclusions are presented in chapter 11 . 


\section{Formulation of the Problem}

The model configuration, Fig. 1 shows two fluids of uniform densities $\rho_{1}$ and $\rho_{2}$, flowing above a fluid of density $\rho_{3}$ where $\rho_{1}<\rho_{2}<\rho_{3}$. The basic flow is taken to be geostrophic in the upper two layers, parallel to the $x$-axis, and stagnant in the bottom layer. The interface between the upper two layers intersects the surface at $y=0$ and their depths approach constant values, $H_{1}$ and $H_{2}$, as $y \rightarrow \pm \infty$ for an "isolated" front. A "coastal" front terminates at $y=y_{c}$ where the depth is $h_{2}\left(y_{c}\right) \leq H_{2}$. The model domain is divided into two zones: to the right of the front (from $y=0$ to $y=\infty$ for the isolated front, from $y=0$ to $y=y_{c}$ for the coastal front) is a two-layer fluid defined as Zone $I$ and to the left (from $y=-\infty$ to $y=0$ ) is a three-layer fluid defined as Zone II. Let $\gamma$ be the ratio of the total depth $\left(H_{T}\right)$ to the top layer thickness $\left(H_{1}\right)$ and $\delta$ be the ratio of the thermocline layer thickness $\left(H_{2}\right)$ to that of the top layer $\left(H_{1}\right)$ at $y=-\infty$ so that, after some minor manipulations, the bottom layer thickness becomes $H_{1}(\gamma-1-\delta)$ at $y=-\infty$, and $H_{1}(\gamma-\delta)$ at $y=\infty$ for the isolated front, $h_{2} \leq H_{1}(\gamma-\delta)$ at $y=y_{c}$ for the coastal front.

The variables are made non-dimensional as shown

$$
\begin{gathered}
t^{*}=t f^{-1} \\
x^{*}=x \sqrt{g \epsilon_{21} H_{1}} f^{-1}, \quad y^{*}=y \sqrt{g \epsilon_{21} H_{1}} f^{-1}, \\
u^{*}=u \sqrt{g \epsilon_{21} H_{1}}, \quad v^{*}=v \sqrt{g \epsilon_{21} H_{1}}, \\
\eta_{1}^{*}=\eta_{1} \epsilon_{21} H_{1}, \quad h_{1}^{*}=h_{1} H_{1}, \\
\eta_{2}^{*}=\eta_{2} \epsilon_{21} H_{1}, \quad h_{2}^{*}=h_{2} H_{2},
\end{gathered}
$$


Figure 1: The configuration for the three-layer model: (a) isolated front, (b) coastal front. 


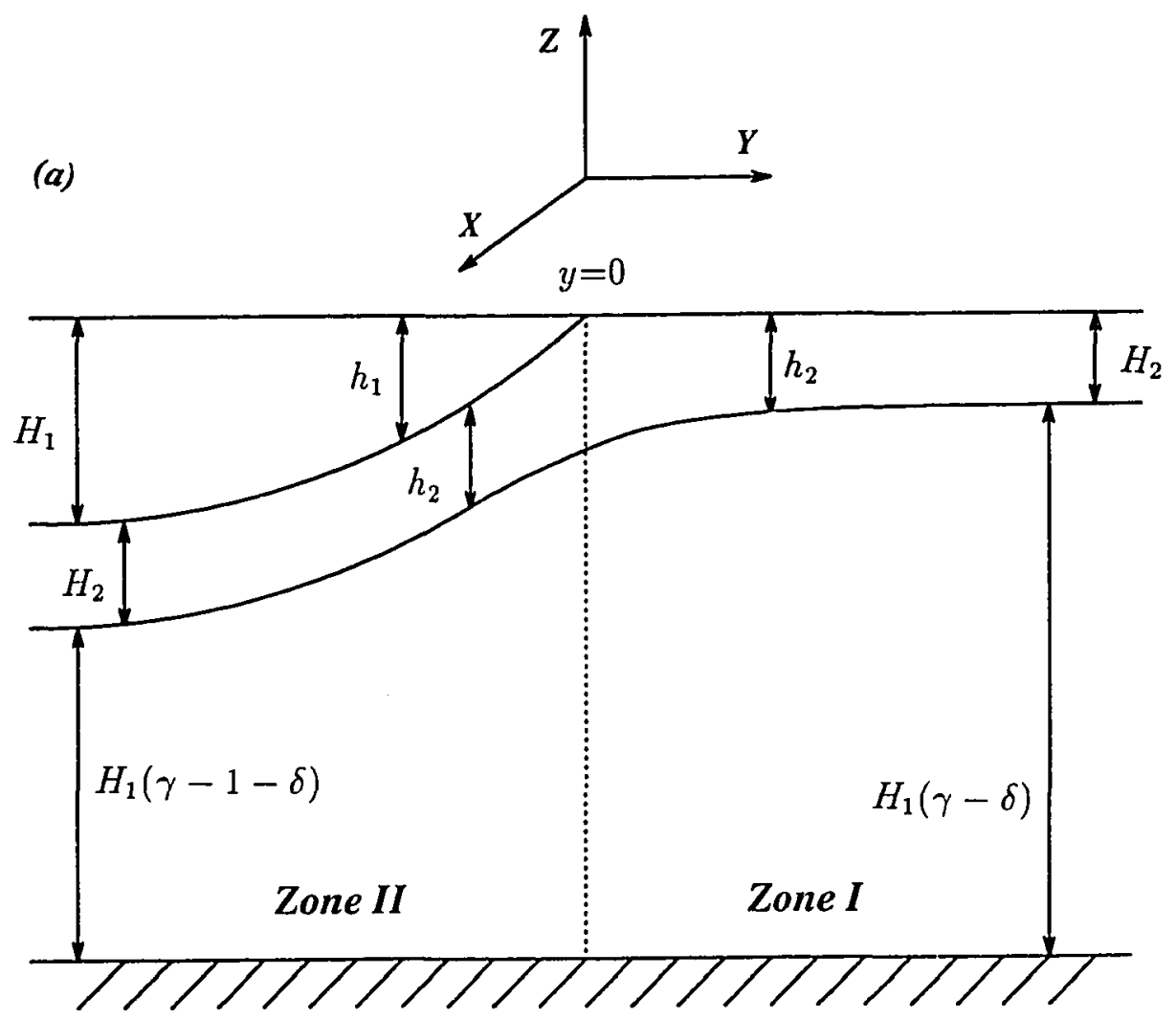




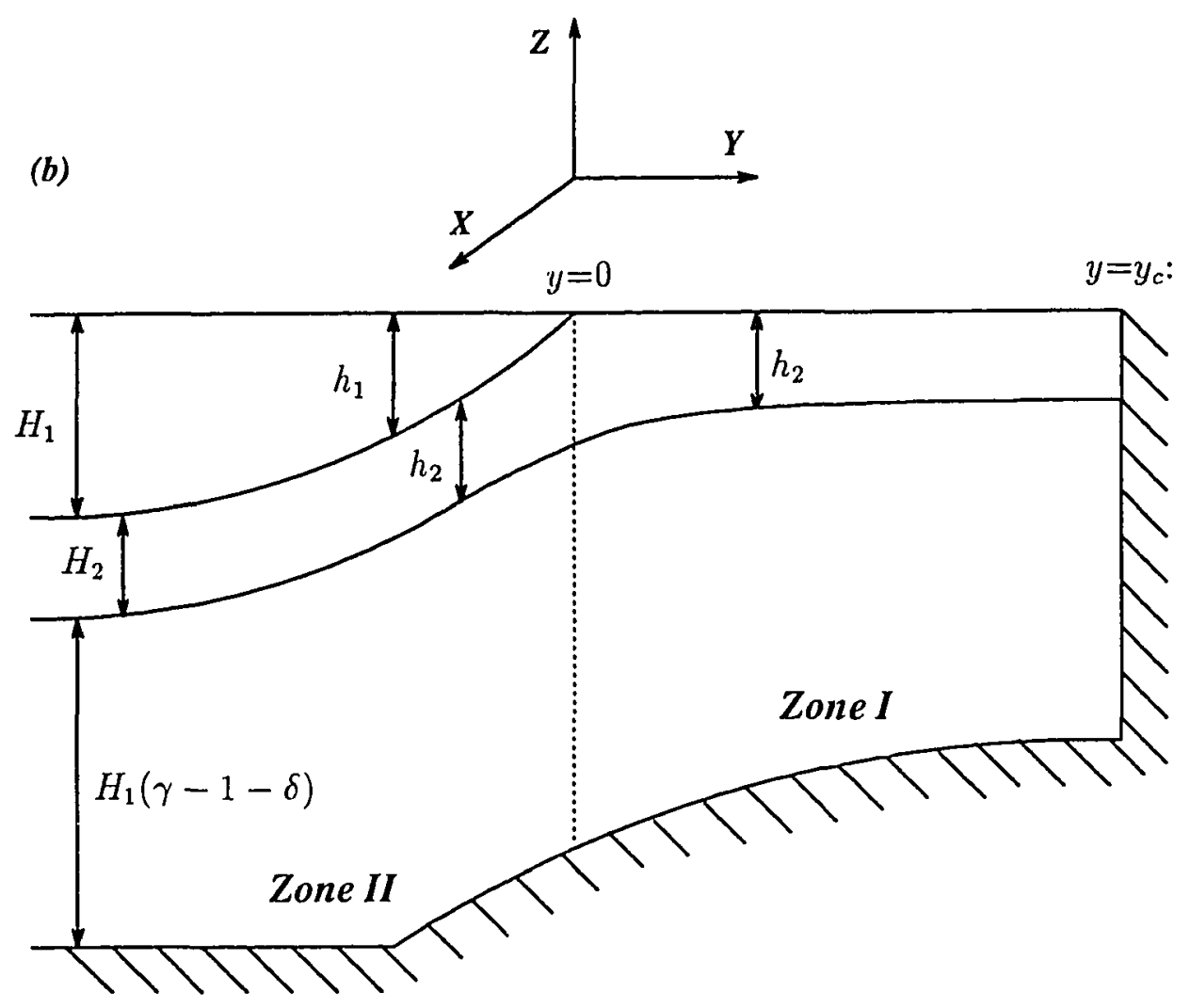


where $f$ is the Coriolis parameter, $g$ is acceleration of gravity, $h_{1}^{*}$ and $h_{2}^{*}$ are the dimensional layer thicknesses of top and thermocline layers, $\eta_{1}^{*}$ and $\eta_{2}^{*}$ are the free surface elevations for Zone $I I$ and $Z$ one $I$ respectively, and $\epsilon_{21}$ is given by

$$
\epsilon_{21}=1-\frac{\rho_{1}}{\rho_{2}}
$$

Note that the Rossby number $R_{o}$ based on the chosen length and velocity scales is exactly unity, so that the QG constraint $\left(R_{o} \ll 1\right)$ does not apply in the present study.

The non-dimensional horizontal momentum equations on an $f$-plane can then be written as

$$
\begin{aligned}
& \frac{\partial u_{j}}{\partial t}+u_{j} \frac{\partial u_{j}}{\partial x}+v_{j} \frac{\partial u_{j}}{\partial y}-v_{j}=-\frac{\partial p_{j}}{\partial x} \\
& \frac{\partial v_{j}}{\partial t}+u_{j} \frac{\partial v_{j}}{\partial x}+v_{j} \frac{\partial v_{j}}{\partial y}+u_{j}=-\frac{\partial p_{j}}{\partial y}
\end{aligned}
$$

where $j=1,2,3$ represents the top, thermocline and bottom layers, respectively. The continuity equations for the upper two layers $(j=1,2)$ are

$$
\frac{\partial h_{j}}{\partial t}+\frac{\partial}{\partial x}\left(u_{j} h_{j}\right)+\frac{\partial}{\partial y}\left(v_{j} h_{j}\right)=0 .
$$

Using the rigid lid approximation, the continuity equation for the bottom layer becomes

$$
\frac{\partial}{\partial t}\left(\gamma-h_{1}-\delta h_{2}\right)+\frac{\partial}{\partial x}\left[u_{3}\left(\gamma-h_{1}-\delta h_{2}\right)\right]+\frac{\partial}{\partial y}\left[v_{3}\left(\gamma-h_{1}-\delta h_{2}\right)\right]=0 .
$$

where, in Zone $I, h_{1}$ is zero.

The pressure gradients in $Z$ one $I$ are given by

$$
\begin{gathered}
\nabla p_{2}=\nabla \eta_{2}, \\
\nabla p_{3}=\nabla \eta_{2}-\alpha \delta \nabla h_{2}
\end{gathered}
$$

where $\nabla$ is the horizontal gradient operator, $\eta_{2}$ is the free surface elevation, $\alpha=\left(\rho_{3}-\right.$ $\left.\rho_{2}\right) /\left(\rho_{2}-\rho_{1}\right)$ is stratification ratio and $\delta=H_{2} / H_{1}$ is the depth ratio. In Zone $I I$, the 
pressure gradients can be written as

$$
\begin{gathered}
\nabla p_{1}=\nabla \eta_{1}, \\
\nabla p_{2}=\nabla \eta_{1}-\nabla h_{1}, \\
\nabla p_{3}=\nabla \eta_{1}-(1+\alpha) \nabla h_{1}-\alpha \delta \nabla h_{2} .
\end{gathered}
$$

where $\eta_{1}$ is the free surface elevation.

We now specify the total flow to be composed of basic and perturbation components:

$$
\begin{array}{rr}
u_{1}=\bar{u}_{1}+\hat{u}_{1}, & v_{1}=\hat{v}_{1}, \\
u_{2}=\bar{u}_{2}+\hat{u}_{2}, & v_{2}=\hat{v}_{2}, \\
u_{3}=\hat{u}_{3}, & v_{3}=\hat{v}_{3},
\end{array}
$$

where overbar and hat denote basic and perturbation terms respectively. The pressure gradients are also decomposed in a similar way:

$$
\begin{gathered}
\nabla p_{1}=\nabla \bar{p}_{1}+\nabla \hat{p}_{1} \\
\nabla p_{2}=\nabla \bar{p}_{2}+\nabla \hat{p}_{2}, \\
\nabla p_{3}=\nabla \hat{p}_{3} .
\end{gathered}
$$




\section{The Basic Flow}

In the basic state we prescribe geostrophic balance and constant potential vorticity, for both active layers [Stommel, 1965; Csanady, 1982; Huang and Stommel, 1990]. Non-dimensional equations describing this state are:

$$
\left.\begin{array}{c}
\bar{u}_{1}=-(\alpha+1) \bar{h}_{1 y}-\alpha \delta \bar{h}_{2 y} \\
\bar{h}_{1}=1-\bar{u}_{1 y}
\end{array}\right\} y<0,
$$

where $\delta$ and $\alpha$ are defined in section 2 .

For $y<0$, these equations can be reduced to a linear, fourth order ODE for one of the variables, say $\bar{h}_{1}-1$ :

$$
\left[\alpha \delta D^{4}-(1+\alpha \delta+\alpha) D^{2}+1\right]\left(\vec{h}_{1}-1\right)=0
$$

Solutions are exponentials:

$$
\bar{h}_{1}-1=\operatorname{ackp}(\mathrm{r} y)
$$

where

$$
\mathrm{r}_{1,2}=\sqrt{\frac{(\alpha+1+\alpha \delta) \pm \sqrt{(\alpha+1+\alpha \delta)^{2}-4 \alpha}}{2 \alpha \delta}} .
$$


Negative roots are excluded by the boundary conditions $\bar{h}_{1}-1=0$ at $y \rightarrow-\infty$.

At $y>0,\left(\alpha \delta D^{2}-1\right)\left(\bar{h}_{2}-1\right)=0$ so that $\bar{h}_{2}=1+b \exp \left(\mathrm{r}_{3} y\right), \mathrm{r}_{3}=-\sqrt{1 / \alpha \delta}$. The full solution satisfying the boundary conditions at infinity is that:

$$
\begin{aligned}
& \left.\begin{array}{l}
\bar{h}_{1}=a_{1} e^{\mathrm{r}_{1} y}+a_{2} e^{\mathrm{r}_{2} y}+1 \\
\bar{h}_{2}=b_{1} e^{\mathrm{r}_{1} y}+b_{2} e^{\mathrm{r}_{2} y}+1
\end{array}\right\} y \leq 0, \\
& \left.\begin{array}{c}
\bar{h}_{1}=0 \\
\bar{h}_{2}=c_{3} e^{-r_{3} y}+1
\end{array}\right\} y \geq 0,
\end{aligned}
$$

where

$$
b_{i}=\frac{1-\alpha \delta \mathrm{r}_{\mathrm{i}}^{2}}{\alpha \mathrm{r}_{\mathrm{i}}^{2}} a_{i} \quad i=1,2
$$

The constants $a_{1}, a_{2}$ and $c_{3}$ are follow from matching conditions at $y=0: \bar{h}_{1}=0, \bar{h}_{2}$ and $\bar{u}_{2}$ continuous.

$$
\begin{array}{r}
1+a_{1}+a_{2}=0 \\
1+b_{1}+b_{2}=1+c_{3} \\
\mathrm{r}_{1} a_{1}+\mathrm{r}_{2} a_{2}+\delta \mathrm{r}_{1} b_{1}+\delta \mathrm{r}_{2} b_{2}=-\delta \mathrm{r}_{3} c_{3}
\end{array}
$$

For $\alpha=1$ and $\delta=1$, the constants are:

\begin{tabular}{|l|l|}
\hline$a_{1}=-0.381966$ & $a_{2}=-0.618034$ \\
\hline$b_{1}=+0.618034$ & $b_{2}=-0.381966$ \\
\hline$c_{3}=+0.236068$ & $\mathrm{r}_{3}=+1.000000$ \\
\hline $\mathrm{r}_{1}=+1.618030$ & $\mathrm{r}_{2}=+0.618034$ \\
\hline
\end{tabular}

Similarly, the basic state for coastal front is obtained with no-slip boundary condition at the coast [Csanady, 1982]. Fig.2 illustrates the basic state. 
Figure 2: Basic geostrophic flow of the isolated front: (a) Layer thickness, (b) Velocity when $\alpha=1, \delta=1$ and $\gamma=8$. 
(a)
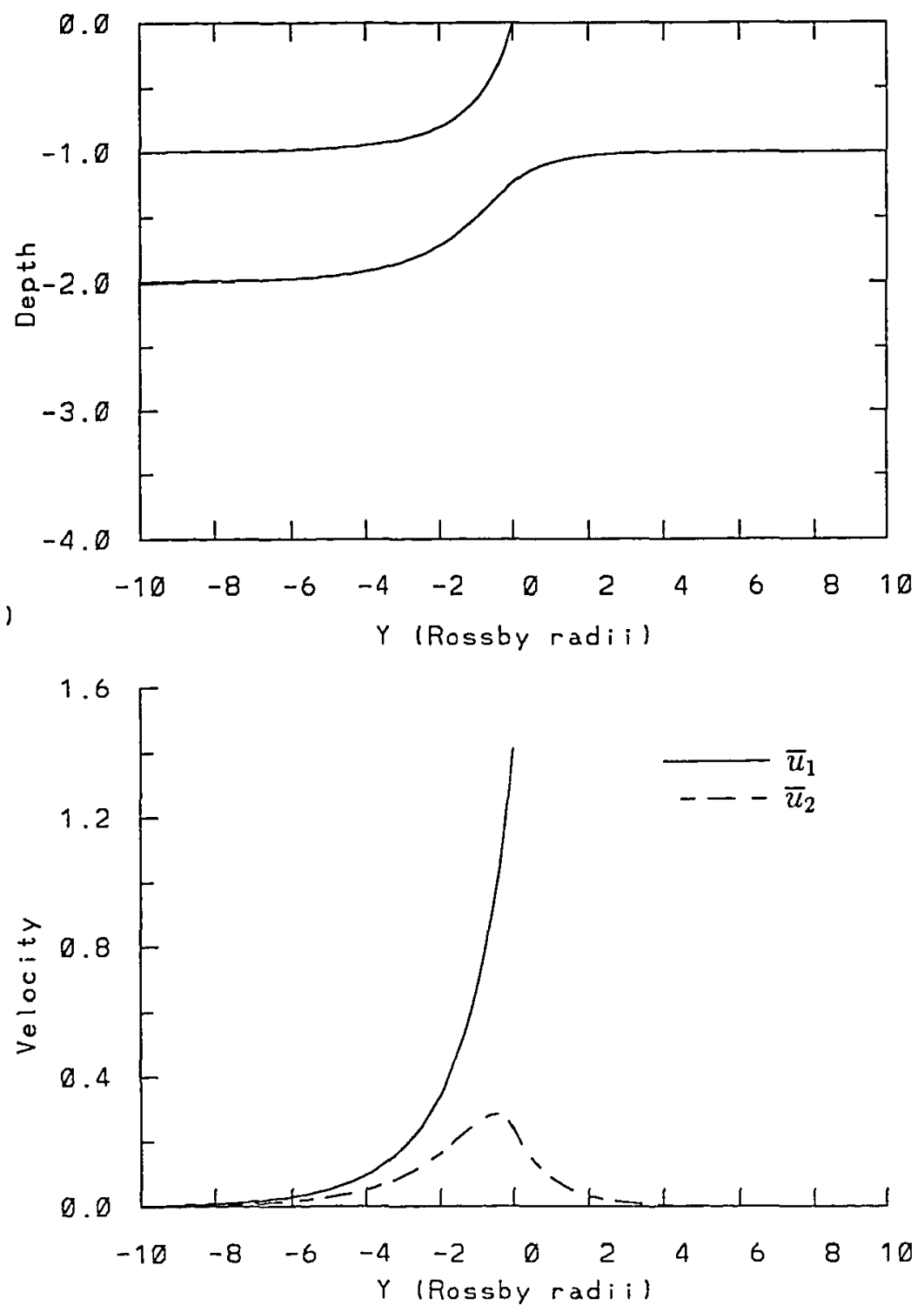


\section{The Perturbation Equations}

We superimpose small wavelike perturbations of the form

$$
(\hat{u}, \hat{v}, \hat{p})=\left[u^{\prime}(y), v^{\prime}(y), p^{\prime}(y)\right] e^{i(\kappa x-\omega t)}
$$

on the basic flow, where $\omega$ is complex frequency and $\kappa$ is wave number. The linearized perturbation equations for the upper two layers $(j=1,2)$ are then

$$
\begin{gathered}
u_{j}^{\prime}\left(\bar{u}_{j} \kappa-\omega\right)+i v_{j}^{\prime}\left(1-\frac{d \bar{u}_{j}}{d y}\right)+\kappa p_{j}^{\prime}=0 \\
u_{j}^{\prime}+i v_{j}^{\prime}\left(\bar{u}_{j} \kappa-\omega\right)+\frac{d p_{j}^{\prime}}{d y}=0 \\
u_{j}^{\prime} \bar{h}_{j} \kappa-i \frac{d}{d y}\left(\bar{h}_{j} v_{j}^{\prime}\right)+h_{j}^{\prime}\left(\bar{u}_{j} \kappa-\omega\right)=0
\end{gathered}
$$

and for the bottom layer

$$
\begin{gathered}
-\omega u_{3}^{\prime}+i v_{3}^{\prime}+\kappa p_{3}^{\prime}=0, \\
u_{3}^{\prime}-i \omega v_{3}^{\prime}+\frac{d p_{3}^{\prime}}{d y}=0, \\
\kappa\left(\gamma-\bar{h}_{1}-\delta \bar{h}_{2}\right) u_{3}^{\prime}-i \frac{d}{d y}\left[\left(\gamma-\bar{h}_{1}-\delta \bar{h}_{2}\right) v_{3}^{\prime}\right]+\omega\left(h_{1}^{\prime}+\delta h_{2}^{\prime}\right)=0 .
\end{gathered}
$$

The momentum equations are used to eliminate $u_{i}^{\prime}$ and $v_{i}^{\prime}$ variables in the continuity equations. The resulting equations in Zone $I I$ are, expressing $h_{i}^{\prime}$ variables in terms of $p_{i}^{\prime}$ variables using equations [(6)-(10)]

$$
\begin{aligned}
\left(\frac{\bar{h}_{1}}{Q_{1}}\right) \frac{d^{2} p_{1}^{\prime}}{d y^{2}}+\left(\frac{\bar{h}_{1}}{Q_{1}}\right)_{y} \frac{d p_{1}^{\prime}}{d y}-\left[\frac{r}{\left(\bar{u}_{1} \kappa-\omega\right)}\left(\frac{\bar{h}_{1}}{Q_{1}}\right)_{y}+\kappa^{2}\left(\frac{\bar{h}_{1}}{Q_{1}}\right)\right] p_{1}^{\prime} \\
=\left(p_{1}^{\prime}-p_{2}^{\prime}\right)
\end{aligned}
$$




$$
\begin{array}{r}
\left(\frac{\bar{h}_{2}}{Q_{2}}\right) \frac{d^{2} p_{2}^{\prime}}{d y^{2}}+\left(\frac{\bar{h}_{2}}{Q_{2}}\right)_{y} \frac{d p_{2}^{\prime}}{d y}-\left[\frac{\kappa}{\left(\bar{u}_{2} \kappa-\omega\right)}\left(\frac{\bar{h}_{2}}{Q_{2}}\right)_{y}+\kappa^{2}\left(\frac{\bar{h}_{2}}{Q_{2}}\right)\right] p_{2}^{\prime} \\
=\frac{(1+\alpha)}{\alpha \delta} p_{2}^{\prime}-\frac{1}{\delta} p_{1}^{\prime}-\frac{1}{\alpha \delta} p_{3}^{\prime} \\
\frac{d^{2} p_{3}^{\prime}}{d y^{2}}-\left[\frac{\bar{h}_{1 y}+\delta \bar{h}_{2 y}}{\left(\gamma-\bar{h}_{1}-\delta \bar{h}_{2}\right)}\right] \frac{d p_{3}^{\prime}}{d y}-\left[\kappa^{2}+\frac{\left(\bar{h}_{1 y}+\delta \bar{h}_{2 y}\right) \kappa}{\omega\left(\gamma-\bar{h}_{1}-\delta \bar{h}_{2}\right)}\right] p_{3}^{\prime} \\
=-\frac{\left(\omega^{2}-1\right)}{\alpha\left(\gamma-\bar{h}_{1}-\delta \bar{h}_{2}\right)}\left(p_{3}^{\prime}-p_{2}^{\prime}\right)
\end{array}
$$

where

$$
Q_{j}=\left(1-\frac{d \bar{u}_{j}}{d y}\right)-\left(\bar{u}_{j} \kappa-\omega\right)^{2}, \quad j=1,2
$$

In Zone $I$, the equations reduce to:

$$
\begin{array}{r}
\left(\frac{\bar{h}_{2}}{Q_{2}}\right) \frac{d^{2} p_{2}^{\prime}}{d y^{2}}+\left(\frac{\bar{h}_{2}}{Q_{2}}\right)_{y} \frac{d p_{2}^{\prime}}{d y}-\left[\frac{\kappa}{\left(\bar{u}_{2} \kappa-\omega\right)}\left(\frac{\bar{h}_{2}}{Q_{2}}\right)_{y}+\kappa^{2}\left(\frac{\bar{h}_{2}}{Q_{2}}\right)\right] p_{2}^{\prime} \\
=\frac{1}{\alpha \delta}\left(p_{2}^{\prime}-p_{3}^{\prime}\right) \\
\frac{d^{2} p_{3}^{\prime}}{d y^{2}}-\left[\frac{\delta \bar{h}_{2 y}}{\left(\gamma-\delta \bar{h}_{2}\right)}\right] \frac{d p_{3}^{\prime}}{d y}-\left[\kappa^{2}+\frac{\delta \bar{h}_{2 y} \kappa}{\omega\left(\gamma-\delta \bar{h}_{2}\right)}\right] p_{3}^{\prime} \\
=-\frac{\left(\omega^{2}-1\right)}{\alpha\left(\gamma-\delta \bar{h}_{2}\right)}\left(p_{3}^{\prime}-p_{2}^{\prime}\right) .
\end{array}
$$

The three equations in $Z$ one $I I$ and two in Zone $I$ are the equations to be integrated, with boundary conditions representing: (a) an isolated front, (b) a coastal front. 


\section{The Isolated Front}

\subsection{Boundary Conditions}

Boundary conditions at $y= \pm \infty$ are that all perturbations vanish:

$$
p_{1}^{\prime}(y)=p_{2}^{\prime}(y)=p_{3}^{\prime}(y)=0, \text { at } \quad y= \pm \infty
$$

At $y=0$, where the front intersects the surface, five boundary conditions must be satisfied. These five boundary conditions are a kinematic boundary condition at $y=0$ expressing continuity of the free surface, plus the continuity of pressure and velocity of the second and third layers. Continuity of surface elevation at the perturbed front $\left(y=y_{f}\right)$ is ensured by pressure continuity. At $y=0$ where $\bar{h}_{1}=0$, a linearized kinematic boundary condition applies:

$$
\frac{D y_{f}}{D t} \simeq i\left(\bar{u}_{1} \kappa-\omega\right) y_{f}=\hat{v}_{1} \text { at } \quad y=0
$$

where $y_{f}$ is the horizontal displacement of the front. To first order in the small quantity $y_{f}$, we get

$$
h_{1}\left(y_{f}\right)=0=h_{1}^{\prime}(0)+\frac{d \bar{h}_{1}}{d y}(0) y_{f} .
$$

Substitution of $y_{f}$ from (41) into this equation gives

$$
i \frac{d \bar{h}_{1}}{d y}(0) v_{1}^{\prime}-h_{1}^{\prime}(0)\left(\bar{u}_{1} \kappa-\omega\right)=0 .
$$

The momentum equations $[(28)-(29)]$ are combined to obtain an equation for $v_{1}^{\prime}$ in terms of $p_{1}^{\prime}$ and $p_{1 y}^{\prime}$, and by substituting $p_{1}^{\prime}-p_{2}^{\prime}$ for $h_{1}^{\prime},(43)$ becomes

$$
\frac{d p_{1}^{\prime}}{d y}(0)+\left[\frac{\left(\bar{u}_{1}(0) \kappa-\omega\right)^{2}}{\bar{h}_{1 y}(0)}-\frac{\kappa}{\left(\bar{u}_{1}(0) \kappa-\omega\right)}\right] p_{1}^{\prime}(0)-\frac{\left(\bar{u}_{1}(0) \kappa-\omega\right)^{2}}{\bar{h}_{1 y}(0)} p_{2}^{\prime}(0)=0
$$


The continuity of pressure of the second layer is

$$
p_{2}^{I I}\left(y_{f}\right)=p_{2}^{I}\left(y_{f}\right)
$$

where superscripts $I, I I$ indicate $Z$ one $I$ and Zone $I I$ respectively. A Taylor expansion of $p_{2}^{I I}\left(y_{f}\right)$ about $y=0$, after linearization, gives

$$
p_{2}^{I I}\left(y_{f}\right)=y_{f} \frac{d \bar{p}_{2}^{I I}}{d y}(0)+\bar{p}_{2}^{I I}(0)+p_{2}^{I I^{\prime}}(0)
$$

Similarly, for $p_{2}^{I}\left(y_{f}\right)$ we get

$$
p_{2}^{I}\left(y_{f}\right)=y_{f} \frac{d \bar{p}_{2}^{I}}{d y}(0)+\bar{p}_{2}^{I}(0)+p_{2}^{I^{\prime}}(0)
$$

Substituting [(46)-(47)] into (45) and using the continuity of pressure and the pressure gradient of the basic flow at $y=0$, we get

$$
p_{2}^{I I^{\prime}}(0)=p_{2}^{I^{\prime}}(0)
$$

The continuity of surface elevation:

$$
\eta_{1}^{I I}\left(y_{f}\right)=\eta_{2}^{I}\left(y_{f}\right)
$$

gives the same boundary condition we found from the continuity of second layer pressure since $p_{1}\left(y_{f}\right)=p_{2}\left(y_{f}\right)$ at $y=y_{f}$ where $h_{1}=0$ (see equations $[(8)-(9)]$ ). The continuity of third layer pressure gives

$$
p_{3}^{I^{\prime}}(0)=p_{3}^{I^{\prime}}(0)
$$

Finally, the continuity of cross-frontal velocity in the second and third layers, after linearization, gives

$$
\begin{aligned}
& v_{2}^{I I^{\prime}}(0)=v_{2}^{I^{\prime}}(0) \\
& v_{3}^{I I^{\prime}}(0)=v_{3}^{I^{\prime}}(0)
\end{aligned}
$$

since the basic cross-frontal velocity is assumed to be zero everywhere. The horizontal perturbation equations $[(28)-(29)]$ and $[(31)-(32)]$ give equations for $v_{2}^{\prime}$ and $v_{3}^{\prime}$ in terms 
of $p^{\prime}$ variables. With the boundary condition (48), they are then substituted into equations $[(51)-(52)]$ to yield:

$$
\begin{aligned}
& \frac{d p_{2}^{I I^{\prime}}}{d y}(0)=\frac{d p_{2}^{I^{\prime}}}{d y}(0), \\
& \frac{d p_{3}^{I I^{\prime}}}{d y}(0)=\frac{d p_{3}^{I^{\prime}}}{d y}(0) .
\end{aligned}
$$

The five boundary conditions rewritten in terms of the pressure in zones $I$ and $I I$ are therefore,

$$
\begin{aligned}
\frac{d p_{1}^{\prime}}{d y}(0)+\left[\frac{\left(\bar{u}_{1}(0) \kappa-\omega\right)^{2}}{\bar{h}_{1 y}(0)}-\frac{\kappa}{\left(\bar{u}_{1}(0) \kappa-\omega\right)}\right] p_{1}^{\prime}(0)-\frac{\left(\bar{u}_{1}(0) \kappa-\omega\right)^{2}}{\bar{h}_{1 y}(0)} p_{2}(0)^{\prime}=0 \\
p_{2}^{I I^{\prime}}(0)=p_{2}^{I^{\prime}}(0) \\
p_{3}^{I I^{\prime}}(0)=p_{3}^{I^{\prime}}(0) \\
\frac{d p_{2}^{I I^{\prime}}}{d y}(0)=\frac{d p_{2}^{I^{\prime}}}{d y}(0), \\
\frac{d p_{3}^{I I^{\prime}}}{d y}(0)=\frac{d p_{3}^{I^{\prime}}}{d y}(0) .
\end{aligned}
$$

Together with the five conditions expressed by equation (40), we now have a total of 10 boundary conditions for 5 second order ODEs.

\subsection{Eigenvalue Problem}

As $y$ goes to $-\infty$, the governing equations for Zone $I I$ reduce to three homogeneous constant coefficient ODEs with simple exponential solutions. The boundary conditions at $y \rightarrow-\infty$ :

$$
p_{1}^{\prime}=p_{2}^{\prime}=p_{3}^{\prime}=0 \quad \text { at } \quad y \rightarrow-\infty
$$

suggest that the solutions of the system $[(34)-(36),(38)-(39)]$ can be expressed as the combination of three independent solutions. It is, therefore, convenient to separate the solutions into three terms:

$$
p_{1}^{\prime}=A_{a} p_{1 a}+A_{b} p_{1 b}+A_{c} p_{1 c}
$$




$$
\begin{aligned}
& p_{2}^{\prime}=A_{a} p_{2 a}+A_{b} p_{2 b}+A_{c} p_{2 c} \\
& p_{3}^{\prime}=A_{a} p_{3 a}+A_{b} p_{3 b}+A_{c} p_{3 c}
\end{aligned}
$$

where $A_{a}, A_{b}$ and $A_{c}$ are arbitrary constants. Similarly, as $y \rightarrow+\infty$, the solutions which satisfy boundary conditions:

$$
p_{2}^{\prime}=p_{3}^{\prime}=0, \text { at } y \rightarrow+\infty
$$

are pairs of simple exponential solutions. Therefore, we get

$$
\begin{aligned}
& p_{2}^{\prime}=B_{p} p_{2 p}+B_{m} p_{2 m} \\
& p_{3}^{\prime}=B_{p} p_{3 p}+B_{m} p_{3 m}
\end{aligned}
$$

where $B_{p}$ and $B_{m}$ are arbitrary constants.

Equations [(34)-(36),(38)-(39)] may be numerically integrated using a fourthorder Runge-Kutta scheme. The analytical solutions at $y \rightarrow \pm \infty[(61)-(63),(65)-(66)]$ are used as initial conditions and the solutions are marched from $y= \pm \infty$ to $y=0$, with a trial complex eigenvalue $\omega$ and a fixed wave number $\kappa$. Three non-dimensional parameters $\alpha, \delta$ and $\gamma$ specifying the physical characteristics of the front are prescribed.

At $y=0$, the five boundary conditions $[(55)-(59)]$ are, in matrix form,

$$
\left[\begin{array}{ccccc}
F_{a} & F_{b} & F_{c} & 0 & 0 \\
p_{2 a} & p_{2 b} & p_{2 c} & -p_{2 p} & -p_{2 m} \\
p_{2 y a} & p_{2 y b} & p_{2 y c} & -p_{2 y p} & -p_{2 y m} \\
p_{3 a} & p_{3 b} & p_{3 c} & -p_{3 p} & -p_{3 m} \\
p_{3 y a} & p_{3 y b} & p_{3 y c} & -p_{3 y p} & -p_{3 y m}
\end{array}\right]\left[\begin{array}{c}
A_{a} \\
A_{b} \\
A_{c} \\
B_{p} \\
B_{m}
\end{array}\right]=0
$$

where the variables $F_{a}, F_{b}$ and $F_{c}$ are

$$
F_{a}=p_{1, j u}(0)+\left[\frac{\left(\bar{u}_{1}(0) \kappa-\omega\right)^{2}}{\bar{h}_{1 y}(0)}-\frac{\kappa}{\left(\bar{u}_{1}(0) \kappa-\omega\right)}\right] p_{1 a}(0)-\frac{\left(\bar{u}_{1}(0) \kappa-\omega\right)^{2}}{\bar{h}_{1, y}(0)} p_{2 a}(0),
$$




$$
\begin{aligned}
& F_{b}=p_{1 y b}(0)+\left[\frac{\left(\bar{u}_{1}(0) \kappa-\omega\right)^{2}}{\bar{h}_{1 y}(0)}-\frac{\kappa}{\left(\bar{u}_{1}(0) \kappa-\omega\right)}\right] p_{1 b}(0)-\frac{\left(\bar{u}_{1}(0) \kappa-\omega\right)^{2}}{\bar{h}_{1 y}(0)} p_{2 b}(0), \\
& F_{c}=p_{1 y c}(0)+\left[\frac{\left(\bar{u}_{1}(0) \kappa-\omega\right)^{2}}{\bar{h}_{1 y}(0)}-\frac{\kappa}{\left(\bar{u}_{1}(0) \kappa-\omega\right)}\right] p_{1 c}(0)-\frac{\left(\bar{u}_{1}(0) \kappa-\omega\right)^{2}}{\bar{h}_{1 y}(0)} p_{2 c}(0),
\end{aligned}
$$

respectively. The determinant of the matrix should vanish in order for non-trivial eigenfunctions to exist: this yields an equation for the calculation of the complex eigenvalue $\omega$. The values of eigenfunctions at $y=0$ obtained from the numerical integrations are then used to calculate the determinant and correct a trial eigenvalue $\omega$ using Muller's method [Gerald and Wheatly, 1984]. The integration procedure is repeated until the relative error is reduced to an order of $10^{-8}$. 


\section{The Coastal Front}

If the fronts are located in a coastal area, the influence of bottom topography should not be neglected. Therefore, the bottom topography $h_{B}^{*}$ is non-dimensionalized as $H_{1} h_{B}$. The continuity equation in the bottom layer then becomes

$$
\frac{\partial}{\partial t}\left(\gamma-h_{1}-\delta h_{2}\right)+\frac{\partial}{\partial x}\left[u_{3}\left(\gamma-h_{1}-\delta h_{2}-h_{B}\right)\right]+\frac{\partial}{\partial y}\left[v_{3}\left(\gamma-h_{1}-\delta h_{2}-h_{B}\right)\right]=0
$$

The horizontal momentum equations and the continuity equations in the upper two layers remain unchanged. Accordingly, the governing equation for the bottom layer in Zone $I I$ is

$$
\begin{array}{r}
\frac{d^{2} p_{3}^{\prime}}{d y^{2}}-\left[\frac{\bar{h}_{1 y}+\delta \bar{h}_{2 y}+h_{B y}}{\left(\gamma-\bar{h}_{1}-\delta \bar{h}_{2}-h_{B}\right)}\right] \frac{d p_{3}^{\prime}}{d y}-\left[\kappa^{2}+\frac{\left(\bar{h}_{1 y}+\delta \bar{h}_{2 y}+h_{B y}\right) \kappa}{\omega\left(\gamma-\bar{h}_{1}-\delta \bar{h}_{2}-h_{B}\right)}\right] p_{3}^{\prime} \\
=-\frac{\left(\omega^{2}-1\right)}{\alpha\left(\gamma-\bar{h}_{1}-\delta \bar{h}_{2}-h_{B}\right)}\left(p_{3}^{\prime}-p_{2}^{\prime}\right)
\end{array}
$$

and in Zone $I$

$$
\begin{aligned}
\frac{d^{2} p_{3}^{\prime}}{d y^{2}}-\left[\frac{\delta \bar{h}_{2 y}+h_{B}}{\left(\gamma-\delta \bar{h}_{2}-h_{B}\right)}\right] & \frac{d p_{3}^{\prime}}{d y}-\left[\kappa^{2}+\frac{\left(\delta \bar{h}_{2 y}+h_{B}\right) \kappa}{\omega\left(\gamma-\delta \bar{h}_{2}-h_{B}\right)}\right] p_{3}^{\prime} \\
& =-\frac{\left(\omega^{2}-1\right)}{\alpha\left(\gamma-\delta \bar{h}_{2}-h_{B}\right)}\left(p_{3}^{\prime}-p_{2}^{\prime}\right) .
\end{aligned}
$$

\subsection{Boundary Conditions}

If a vertical wall limits the two-layer zone at $y=y_{c}$, the velocity component normal to the wall should vanish at $y=y_{c}$ :

$$
v_{2}^{\prime}=v_{3}^{\prime}=0 . \quad \text { at } \quad y=y_{c}
$$


The horizontal perturbation equations $[(28)-(29)]$ and $[(31)-(32)]$ give equations for $v_{2}^{\prime}$ and $v_{3}^{\prime}$ in terms of pressure variables $p_{2}^{\prime}$ and $p_{3}^{\prime}$ :

$$
\begin{gathered}
v_{2}^{\prime}=\frac{i \kappa p_{2}^{\prime}-i\left(\bar{u}_{2} \kappa-\omega\right) p_{2 y}^{\prime}}{Q_{2}} \\
v_{3}^{\prime}=\frac{i \kappa p_{3}^{\prime}+i \omega p_{3 y}^{\prime}}{\left(1-\omega^{2}\right)}
\end{gathered}
$$

where $Q_{2}$ is defined in equation (37). Since $\bar{u}_{2}=0$ at $y=y_{c}$, using $[(62)-(63)]$, we finally get the boundary conditions at $y=y_{c}$ :

$$
\begin{aligned}
& p_{2}^{\prime}=-\left(\frac{\omega}{\kappa}\right) \frac{d p_{2}^{\prime}}{d y} \quad \text { at } y=y_{c}, \\
& p_{3}^{\prime}=-\left(\frac{\omega}{\kappa}\right) \frac{d p_{3}^{\prime}}{d y} \text { at } y=y_{c},
\end{aligned}
$$

\subsection{Eigenvalue Problem}

Equations [(34)-(35),(72)] and [(38),(73)] can be integrated with boundary conditions $[(77)-(78)]$ putting $p_{2}^{\prime}\left(y_{c}\right)$ and $p_{3}^{\prime}\left(y_{c}\right)$ into the following forms:

$$
\begin{aligned}
& p_{2}^{\prime}=B_{1} p_{2 d}, \\
& p_{3}^{\prime}=B_{2} p_{3 d},
\end{aligned}
$$

where $B_{1}$ and $B_{2}$ are arbitrary constants. Without loss of generality, $p_{2 d}$ and $p_{3 d}$ are both set equal to one. The final boundary conditions at $y=0$ are then, in matrix form,

$$
\left[\begin{array}{ccccc}
F_{a} & F_{b} & F_{c} & 0 & 0 \\
p_{2 a} & p_{2 b} & p_{2 c} & -p_{2 d} & 0 \\
p_{2 y a} & p_{2 y b} & p_{2 y c} & -p_{2 y d d} & 0 \\
p_{3 a} & p_{3 b} & p_{3 c} & 0 & -p_{3 l d} \\
p_{3 y a} & p_{3 y b} & p_{3 y c} & 0 & -p_{3 y d}
\end{array}\right]\left[\begin{array}{c}
A_{a} \\
A_{b} \\
A_{c} \\
B_{1} \\
B_{2}
\end{array}\right]=0
$$

where the variables $F_{a}, F_{b}$ and $F_{c}$ are defined in equations [(68)-(70)]. The solution technique for this coastal front is same as that used for the isolated front. 


\section{Calculated Results}

Solutions of the system of equations $[(34)-(36),(38)-(39)]$ have been computed with boundary conditions [(55)-(59)] and basic flow as described in chapter 3 . Here, a test case is chosen with parameters typical of the Gulf Stream west of $77^{\circ} \mathrm{W}$. The layer thicknesses are $H_{1}=500 \mathrm{~m}, H_{2}=500 \mathrm{~m}$ and $H_{T}=4000 \mathrm{~m}$. These yield $\delta=1$ and $\gamma=8$. The mean densities $\left(\sigma_{t}\right)$ in the three layers of $26.90,27.30$ and 27.70 give $\alpha=1.0$ and the internal Rossby radius $R_{d}$ is approximately $30 \mathrm{~km}$. This model configuration with the parameters $(\delta=1, \gamma=8$ and $\alpha=1)$ will serve as a standard case with which the results of the model with different parameter values are compared.

\subsection{Isolated Front}

Eqns. [(34)-(36),(38)-(39)] were solved numerically with given parameters for a range of alongfront wavenumbers $\kappa$. The complex frequency $\omega$, in which the real and imaginary parts indicate the frequency $\omega_{r}$ and growth rate $\omega_{i}$ respectively, was obtained as a function of $\kappa$. They are plotted in Fig.3 as a function of $\kappa$. The growth rate is found to have maximum value $\left(\omega_{i n}\right)$ of 0.0274 at $\kappa=0.43$, monotonically decreasing both at larger and smaller scales. The frequency $\omega$ is purely real above the critical wavenumber $\kappa_{c} \simeq 0.59$ where $\omega_{i}=0$. The values of $\omega_{r}$ are all positive and the phase speed, which is defined as $c=\omega_{r} / \kappa$, is also positive. This shows that the wave propagation is in the downstream direction. The positive 2 nd derivative of the $\omega_{r}(\kappa)$ curve implies that the wave is dispersive with positive group speed so that the energy of the wave also propagates in the downstream direction. 
Figure 3: Isolated front: (a) Frequency of the fastest growing wave as a function of along front wave number $\kappa$, (b) Growth rate of the fastest growing wave as a function of along front wave number $\kappa$. 
(a)

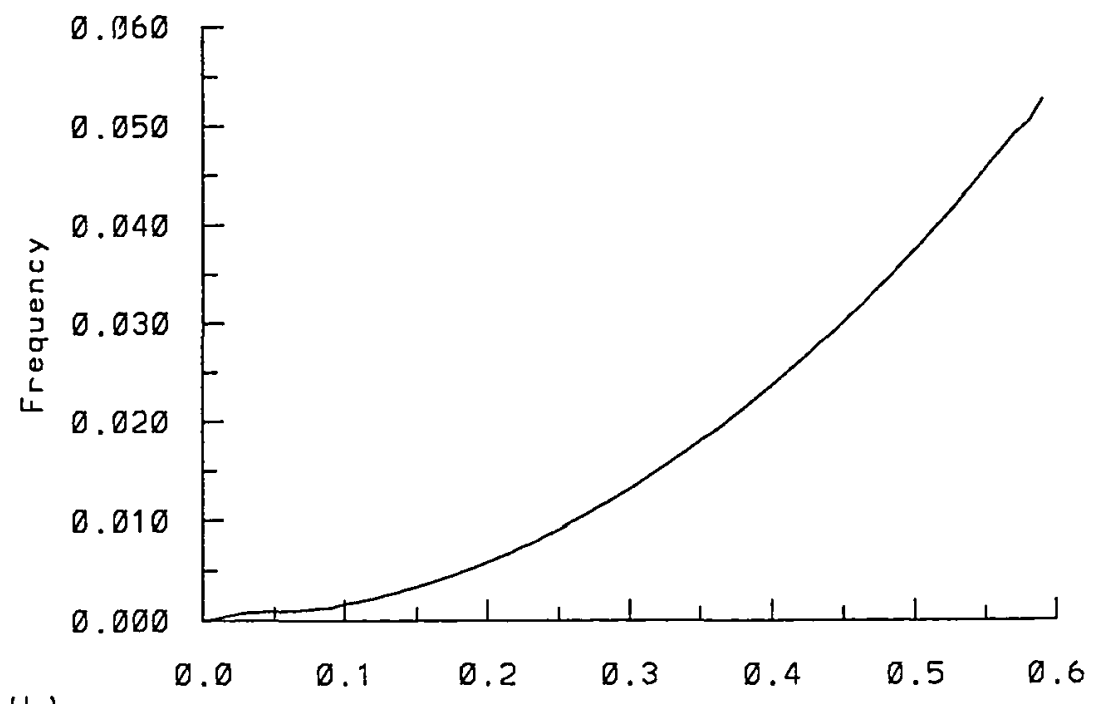

(b)

Along front wavenumber

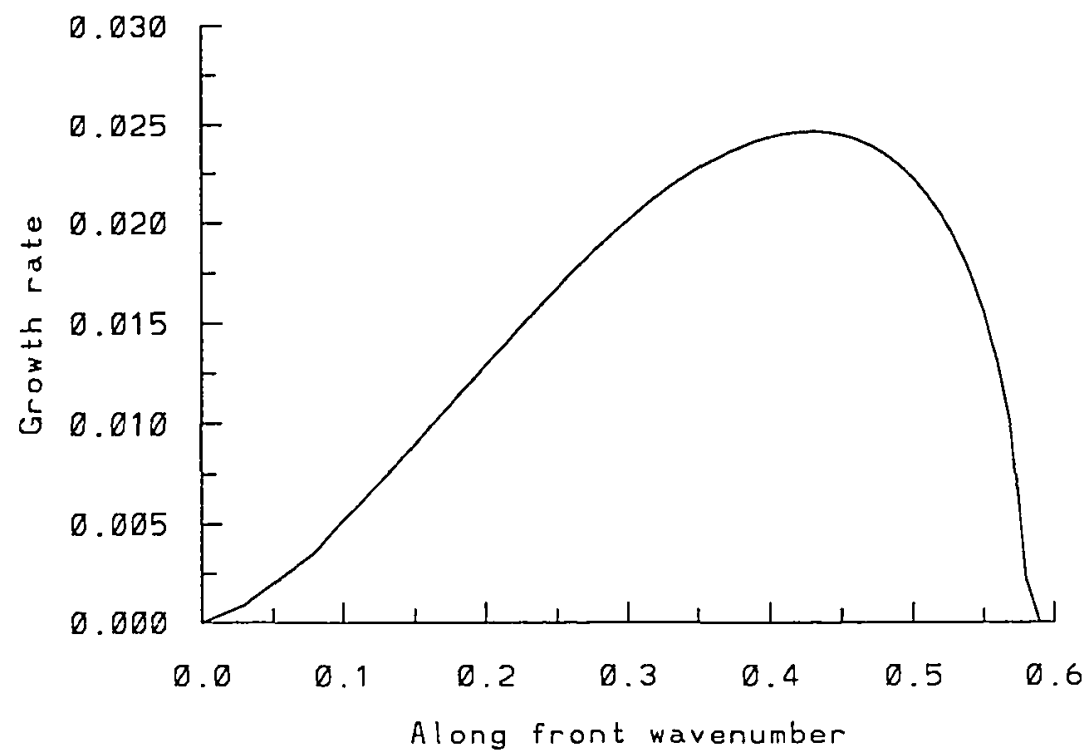


To illustrate how fast this wave propagates and grows, we calculated the dimensional properties of the most unstable wave (the scales were defined in chapter $2)$. The wave number $\kappa$ is non-dimensionalized by $1 / R_{d}$ where $R_{d}$ is found to be approximately $30 \mathrm{~km}$ for this test case. The wavelength of the most unstable wave is, therefore, $438 \mathrm{~km}$. The dimensional e-folding time scale, which indicates the time it takes the unstable wave to grow to $\exp (1)$ times its initial amplitude, can be obtained by multiplying $\omega_{i m}^{-1}$ by $f^{-1}$. To obtain the dimensional phase speed, $\omega_{r m} / \kappa_{m n}$ should be multiplied by $f R_{d}$. For this test case, the most unstable wave has a wavelength of $438 \mathrm{~km}$, an e-folding time scale of 4.2 days and a phase speed of $19 \mathrm{~cm} / \mathrm{sec}$ indicating that the wave propagates in the downstream direction very slowly compared with the mean flow speed.

Before examining the structure of the eigenfunctions, it is important to address some of the limitations of linear instability analysis. The most unstable wave is the wave whose structure is most likely to be observed, since it grows most rapidly until nonlinear effects may change the structure of this linear wave. However, existing initial disturbances may interfere with this scenario. Furthermore, the growth of the perturbations predicted by linear theory is always exponential. Nonlinear processes will eventually alter the exponential growth at a certain time $t_{c}$. Laboratory and field observations suggest that the amplitudes of the unstable waves considered here tend to level off.

The structure of the most unstable wave is displayed in Fig.4. All the values are normalized by the pressure maximum of the first layer since the amplitudes are all arbitrary. Note the difference in the direction of cross-frontal velocities between the lower two layers. Fig.5 illustrates the 2-D structure of the eigenfunctions taking into account phase as well as amplitude. The wavy line shows the displacement of the front, for orientation in comparing phases. 
Figure 4: Isolated front: Eigenfunctions of the most unstable wave of (a) the top layer, (b) the thermocline layer and (c) the bottom layer. 
(a)
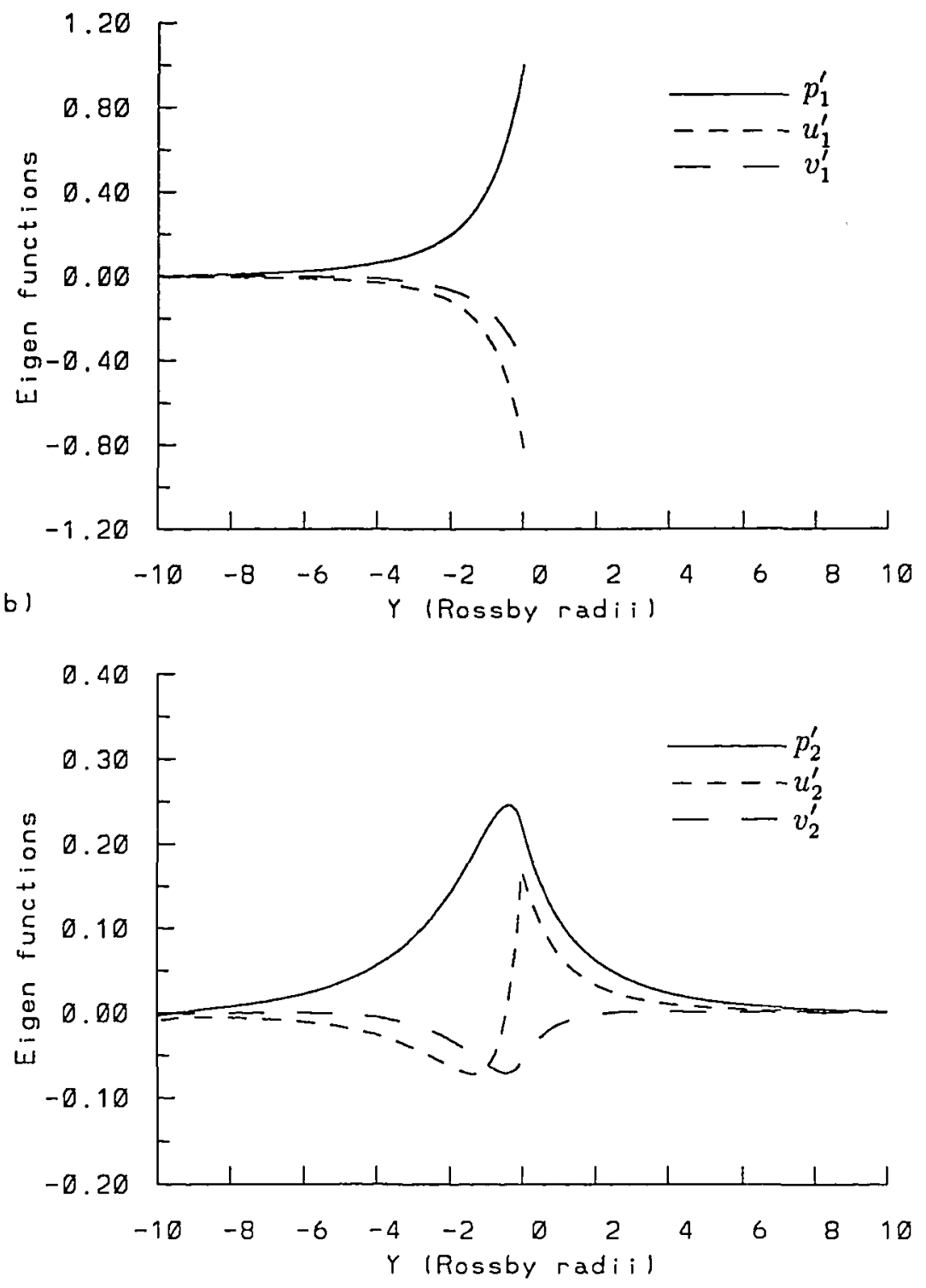
(c)

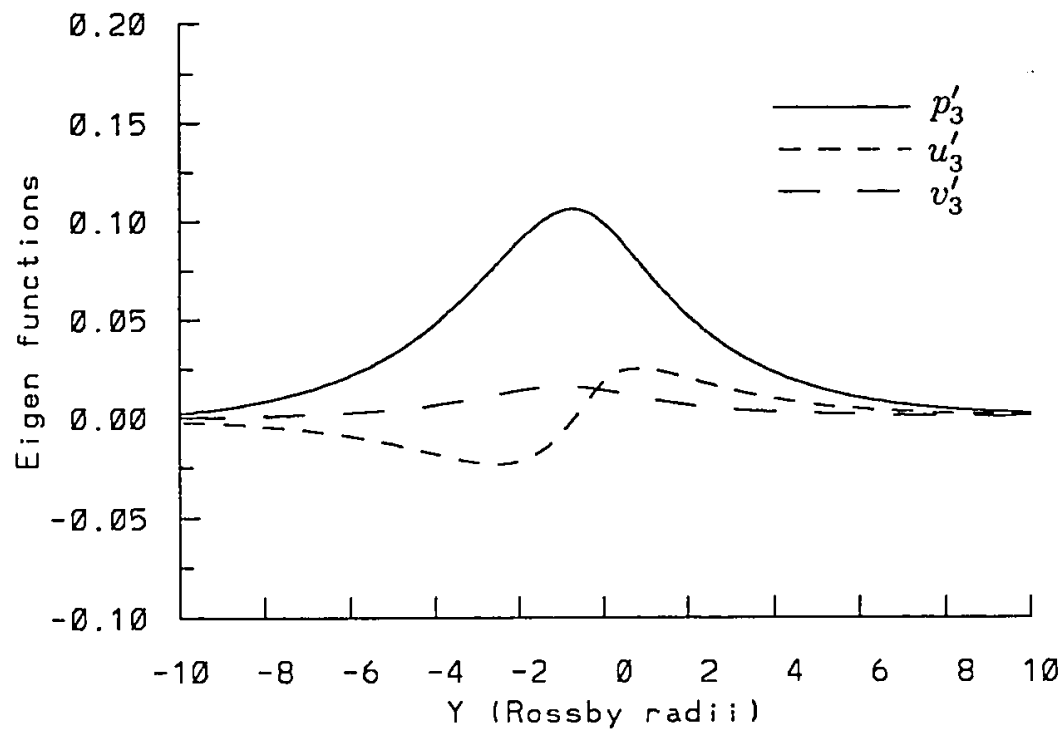


Figure 5: Isolated Front: Two-dimensional structure of the eigenfunctions (contours of pressure and velocity vectors), (a) the top layer: contours from -1.28 to $1.07, \mathrm{CI}=0.21$, $\max$ vector $=0.42$; (b) the thermocline layer: contours from -0.30 to $0.25, \mathrm{CI}=0.05$, $\max$ vector $=0.24$; (c) the bottom layer: contours from -0.11 to $0.09, \mathrm{CI}=0.02$, $\max$ vector $=0.05$, wavy line indicates the phase of the surface front displacement. 
(a)

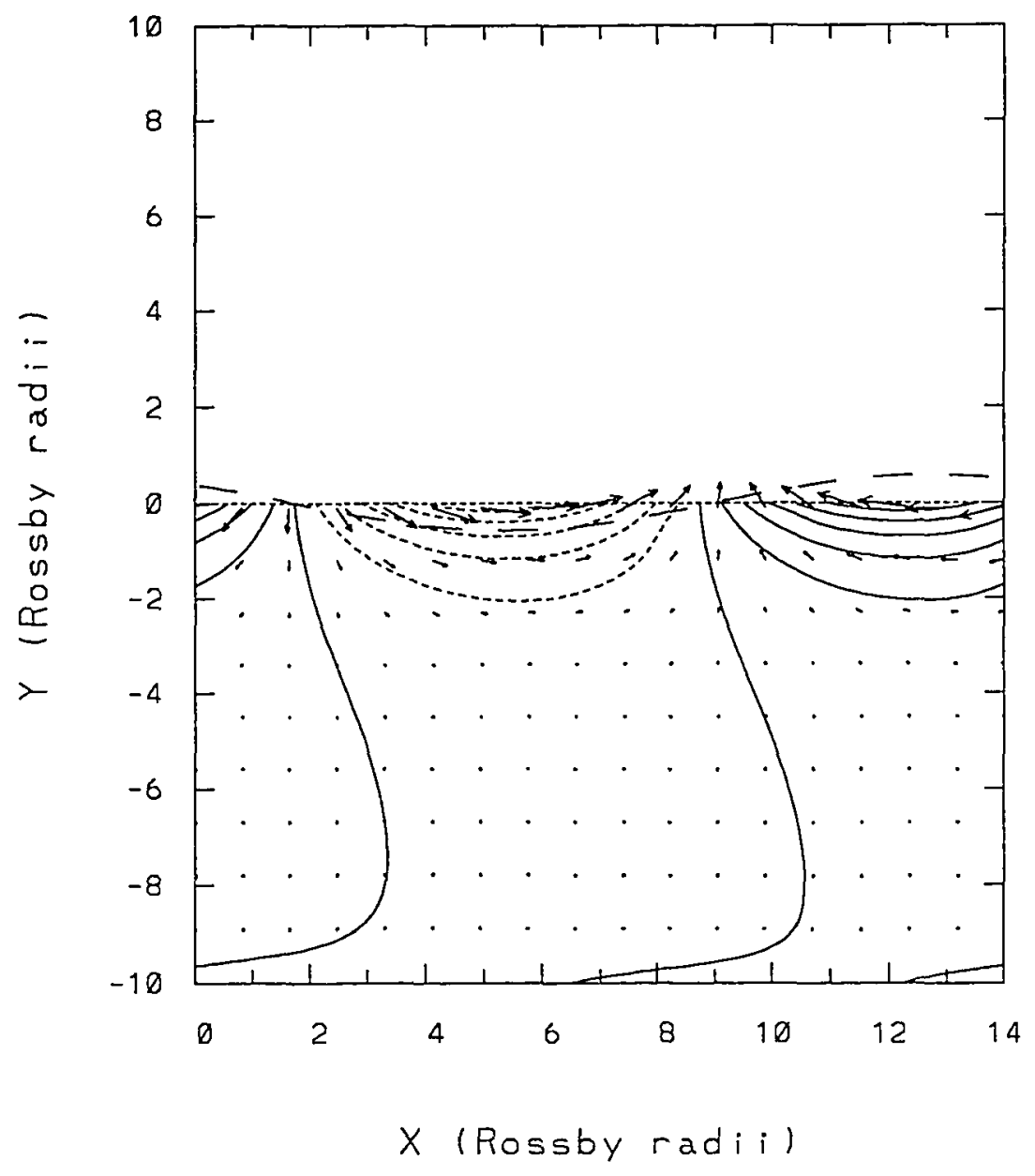


(b)

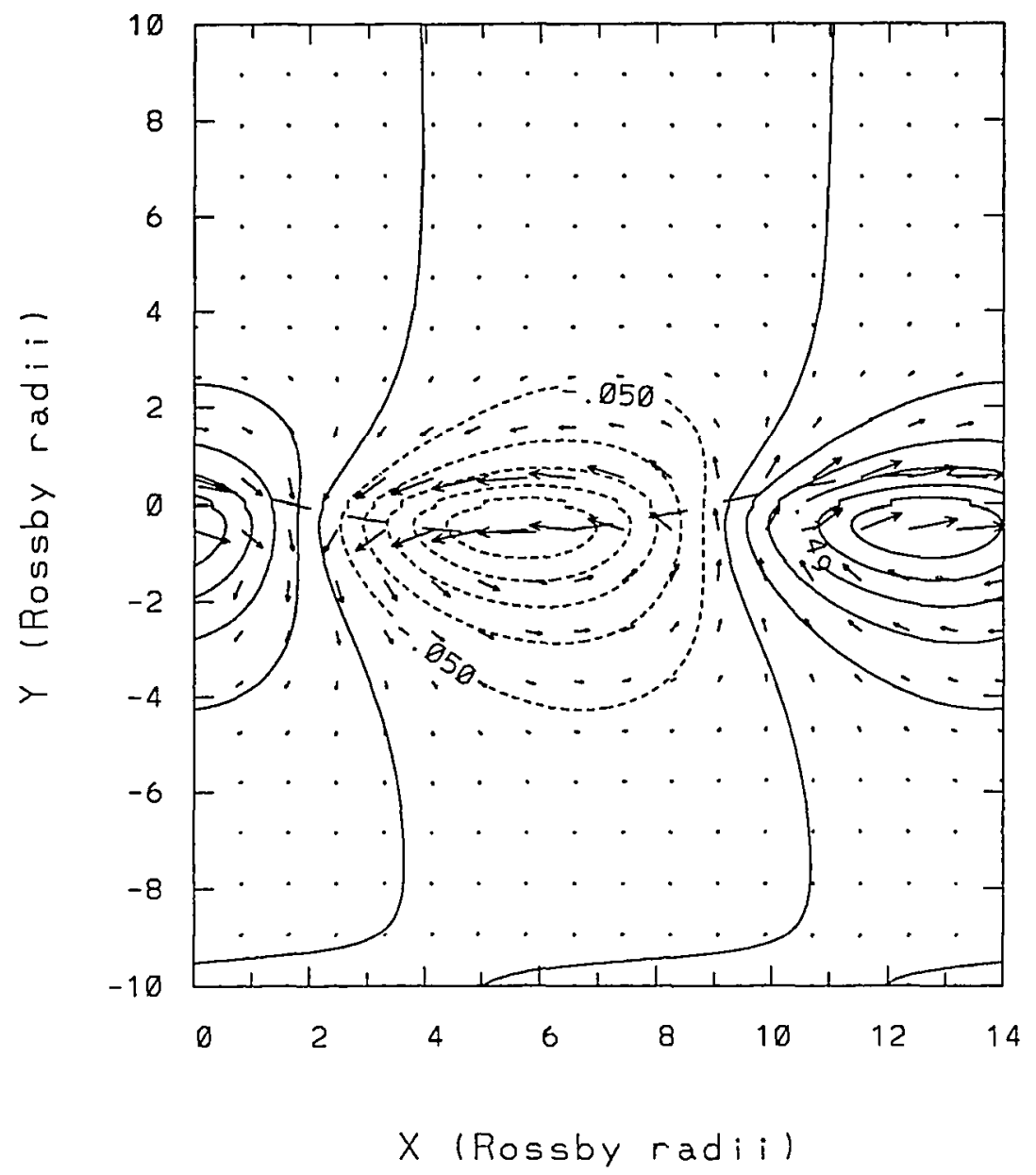


(c)

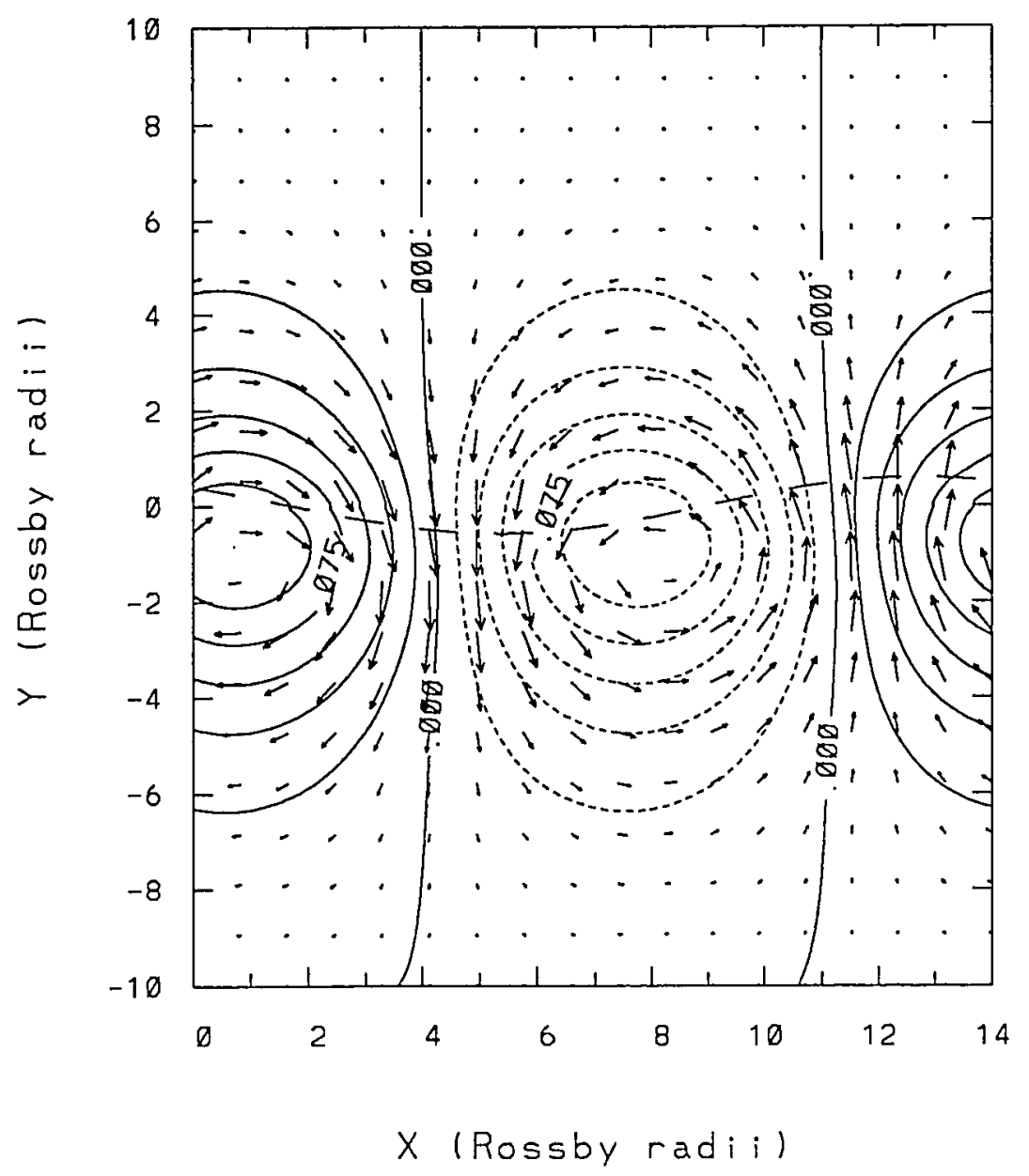


The present model has a set of non-dimensional parameters to be chosen according to the dimensional properties of modeling regions. For simplicity, we only examine the influence of the parameter $\gamma$ which is the ratio of bottom layer to top layer depth. Fig.6 clearly shows the stabilizing influence of increasing value of $\gamma$. The result is as expected in view of the study of Killworth et al [1984]. As the bottom layer thickness increases compared to the upper two layers, the shear between the lower two layers decreases, and with it the growth rate.

\subsection{Coastal Front, Flat Bottom}

The length scale of the two layer zone $y_{c}$ is chosen as six times the Rossby radius, other parameters are the same as for the isolated front. The frequency and growth rate are plotted in Fig.7. The maximum growth rate of 0.0182 at $\kappa_{m}=0.49$ is somewhat smaller than for the isolated front. We obtain a dimensional wavelength for the most unstable wave of $385 \mathrm{~km}$, an e-folding time scale of 6.3 days and a phase speed of 19.2 $\mathrm{cm} / \mathrm{sec}$. The wave is less unstable, the wavelength of the most unstable wave slightly smaller, than for the isolated front. The calculation was carried out again for several values of $y_{c}$. The growth rate remains almost the same as for $y_{c}=6$ except when $y_{c}$ is one or less. Oey [1988] pointed out, on the basis of a numerical study, that the growth rate of frontal instabilities depends primarily on the ratio of the cross stream length of coastal region to the internal Rossby radius ( $y_{c}$ in this study). Similarly to Oey [1988], when $y_{c}>1$, we find that different values of $y_{c}$ neither stabilize nor destabilize the flow. However, when $y_{c} \leq 1$, (not the case for the MAB), the growth rate does decrease rapidly. This may be due to the interference with the cross-frontal volume transport by the side wall, resulting in a stabilization of the front. 
Figure 6: Growth rate of the fastest growing wave as a function of along front wave number $\kappa$, for $\gamma=4,6,8$ : Isolated front. 
(a)
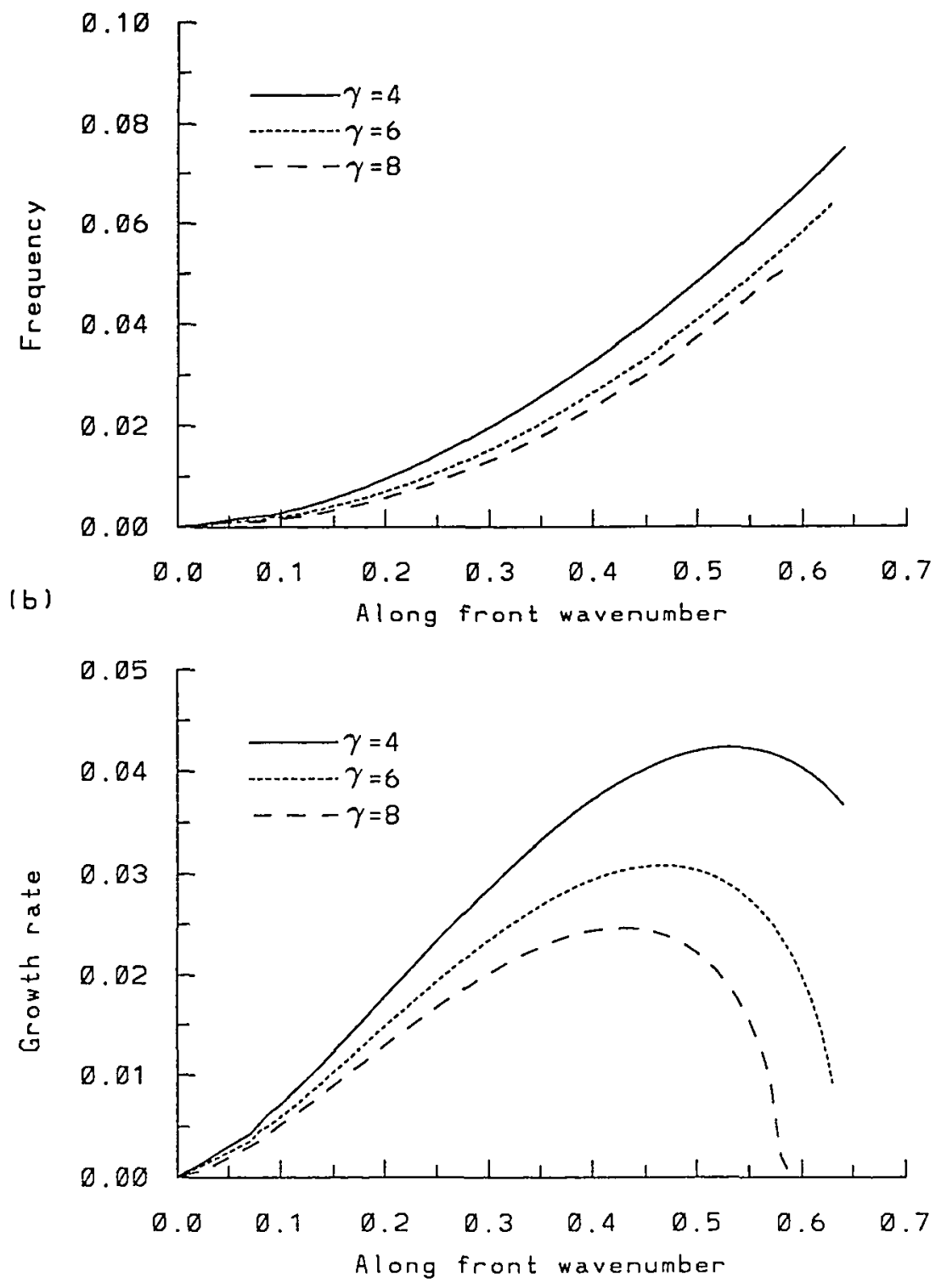

32 
Figure 7: Coastal front, flat bottom: (a) Frequency of the fastest growing wave as a function of along front wave number $\kappa$, (b) Growth rate of the fastest growing wave as a function of along front wave number $\kappa$. 
(a)
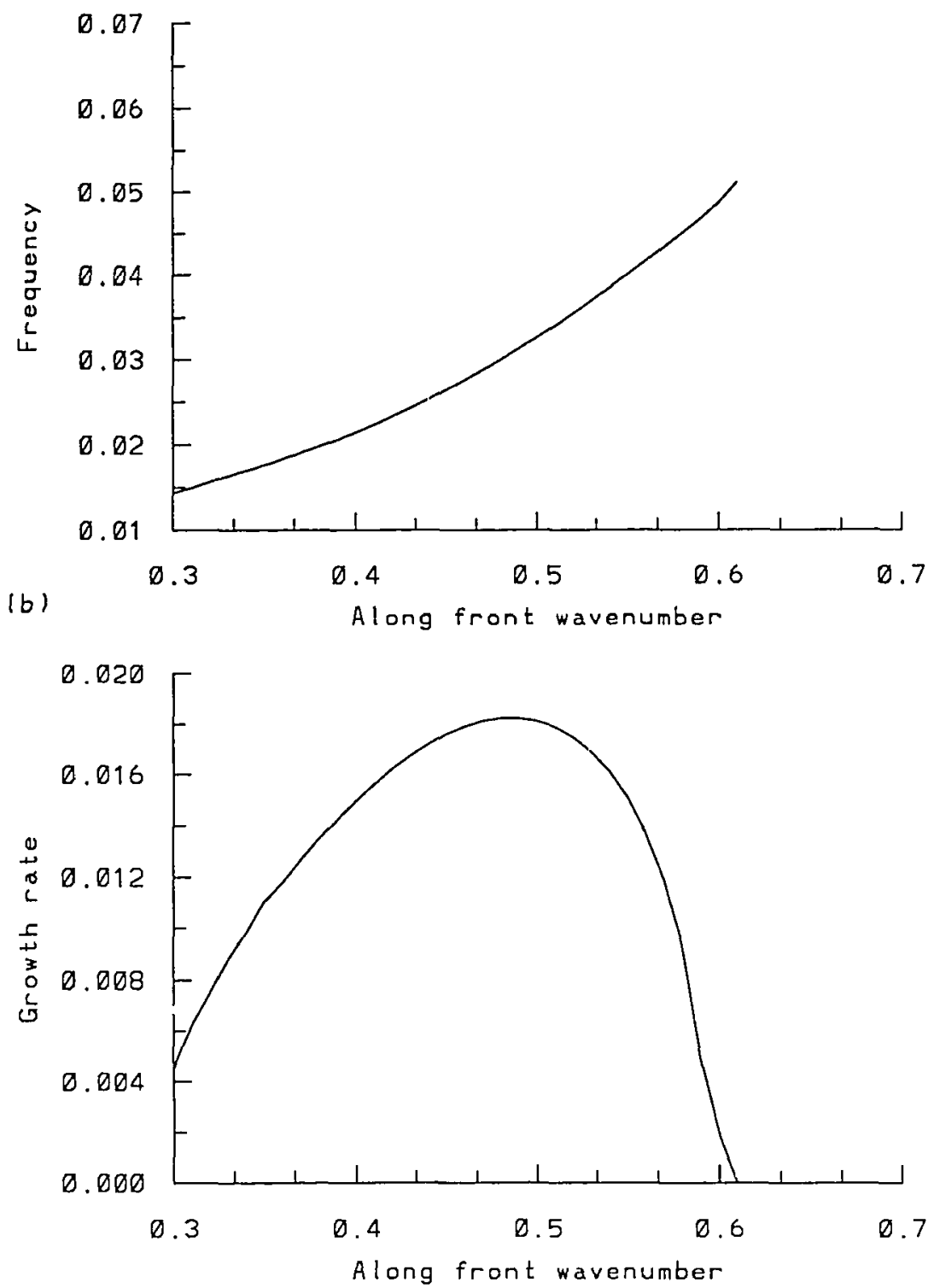


\subsection{Coastal Front, Sloping Bottom}

Since most oceanic fronts are located near coasts, the dynamical effects of sloping bottom topography should also be considered. The influence of bottom topography on frontal instability was first studied by Orlanski [1969]. He used a hyperbolic-tangent function for the shape of the bottom and found a destabilizing effect. Recently, Barth [1987] used a set of approximate equations (Geostrophic Momentum approximation) with linear bottom topography and found a stabilizing effect of the bottom, opposite to Orlanski's result.

Here, we use a hyperbolic tangent function for the shape of the bottom similar to Orlanski's [1969]:

$$
h_{B}=H_{0} \tanh \frac{1}{2}(y+1)+H_{0}
$$

where $H_{0}$ is the bottom depth $h_{B}$ at $y=y_{c}$. Fig. 8 shows the bottom topography along with the basic flow for the test case $\left(H_{0}=3\right)$. The distance to the coast, $y_{c}$ is six times the Rossby radius, the rest of the parameters the same as for the flat bottom model. The frequency and growth rate are plotted in Fig.9. The maximum growth rate is 0.0415 at $\kappa_{m}=0.60$. The dimensional wave length of the most unstable wave is about $314 \mathrm{~km}$, the e-folding time scale of 2.8 days and the phase speed of $33.7 \mathrm{~cm} / \mathrm{sec}$. Compared with the flat bottom case, the wave is more unstable, the wavelength of the most unstable wave smaller, the phase speed greater. The eigenfunctions of the fastest growing wave are shown in Figs.10 and 11. Calculations were also made for $H_{0}=2,4$. Fig. 12 shows the growth rates for $H_{0}=2,3$ and 4 . The results show that steeper bottom topography destabilizes the front, and the wavelength of the most unstable wave decreases as the slope of the bottom topography increases.

The total flow (basic flow + perturbations) was obtained for the thermocline layer by assuming that the perturbation velocity is $1 \%$ of the basic flow at the initial time. 
Fig.13 show the time evolution of meandering for one period, in the thermocline layer (wavy lines indicate the evolution of perturbed front $y_{f}$ ). Weak but broad cyclonic eddies develop in the two-layer region (shoreward of the front), in the trough of the meander, behaving a pronounced feature within a wave period. 
Figure 8: Hyperbolic tangential shape of bottom topography for $H_{0}=3$ along with the basic geostrophic frontal structure. 


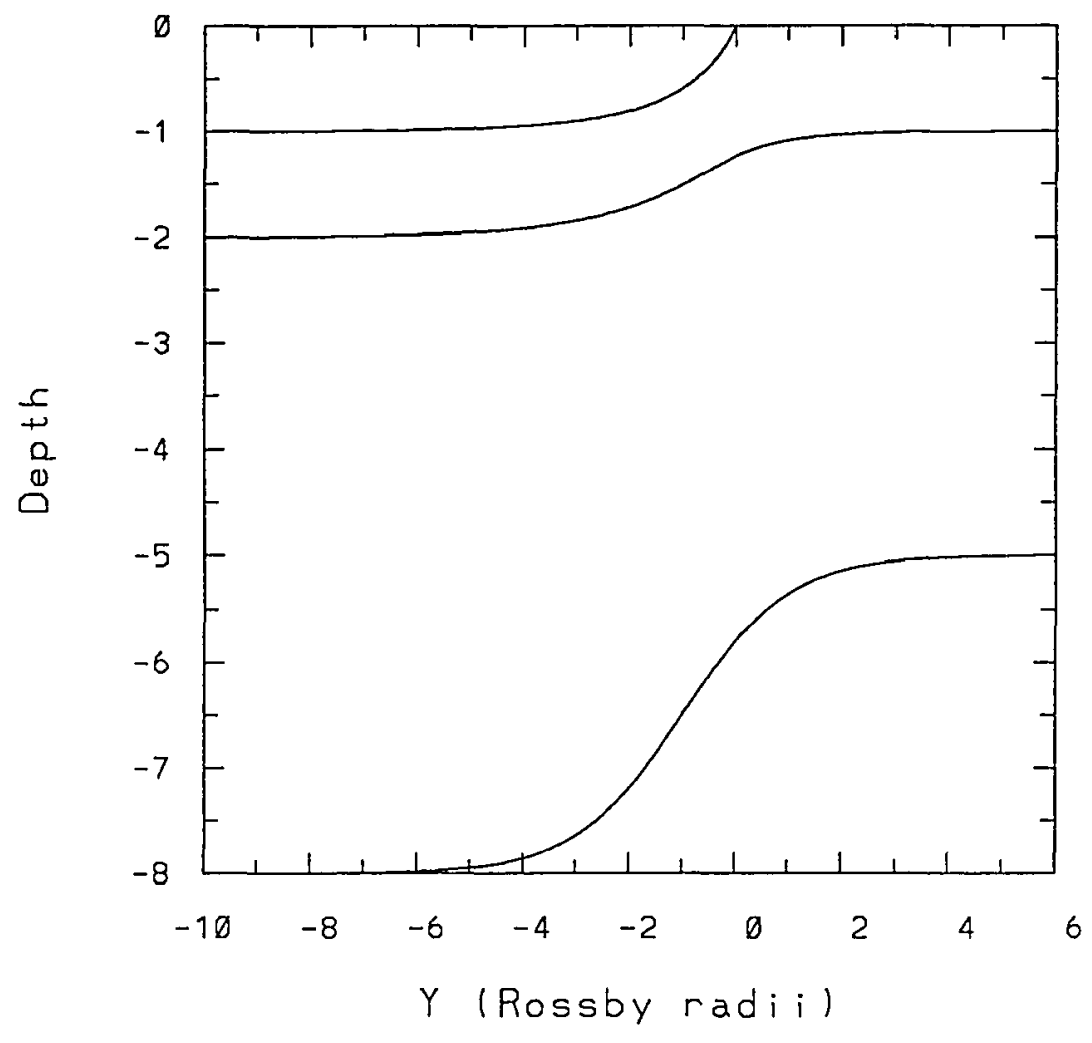


Figure 9: Coastal front, sloping bottom: (a) Frequency of the fastest growing wave as a function of along front wave number $\kappa$, (b) Growth rate of the fastest growing wave as a function of along front wave number $\kappa$. 
(a)
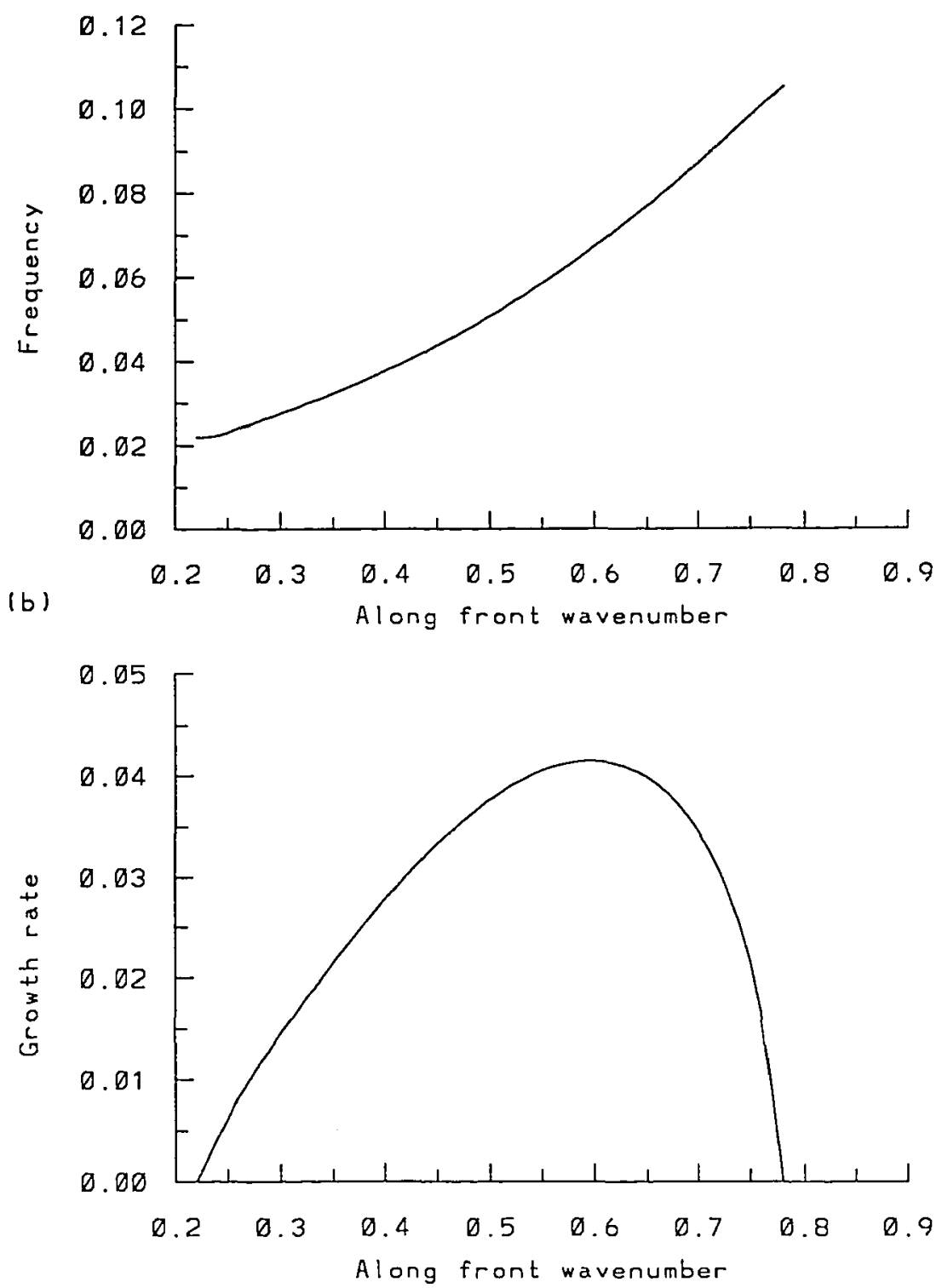
Figure 10: Coastal front, sloping bottom: Eigenfunctions of the most unstable wave of (a) the top layer, (b) the thermocline layer and (c) the bottom layer. 
(a)
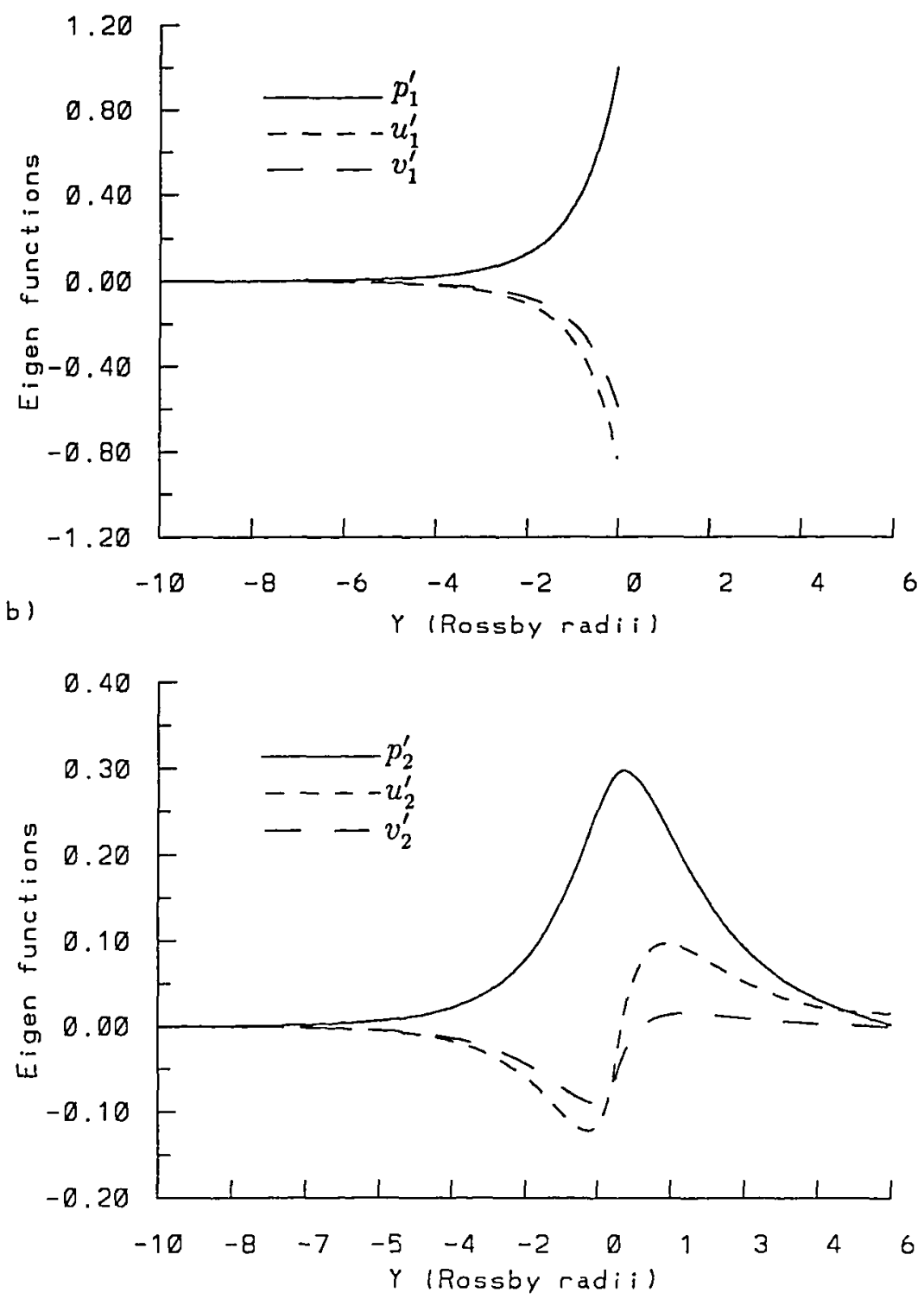
(c)

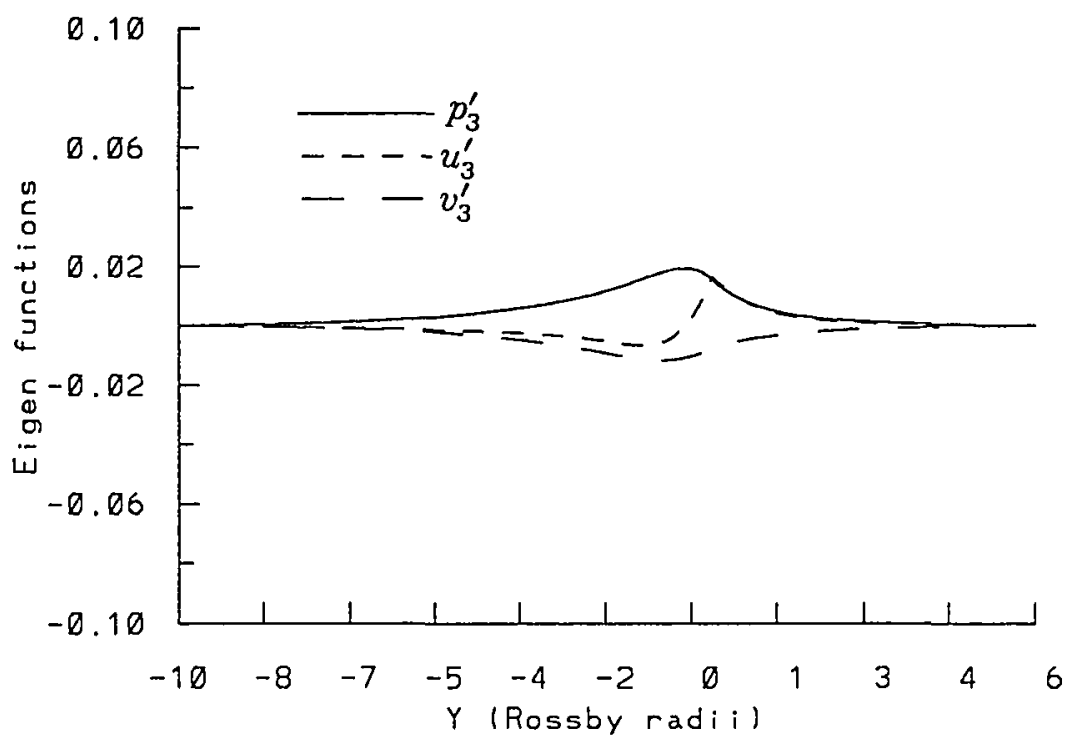


Figure 11: Coastal front, sloping bottom: Two-dimensional structure of the eigenfunctions (contour of pressure and velocity vector), (a) the top layer: contour from -1.26 to $1.05, \mathrm{CI}=0.21$, $\max$ vector $=0.58$; (b) the thermocline layer: contour from -0.31 to $0.26, \mathrm{CI}=0.05$, $\max$ vector $=0.29 ;$ (c) the bottom layer: contour from -0.03 to $0.03, \mathrm{CI}=0.004, \max$ vector $=0.02$, wavy line indicates the phase of the surface front displacement. 
(a)

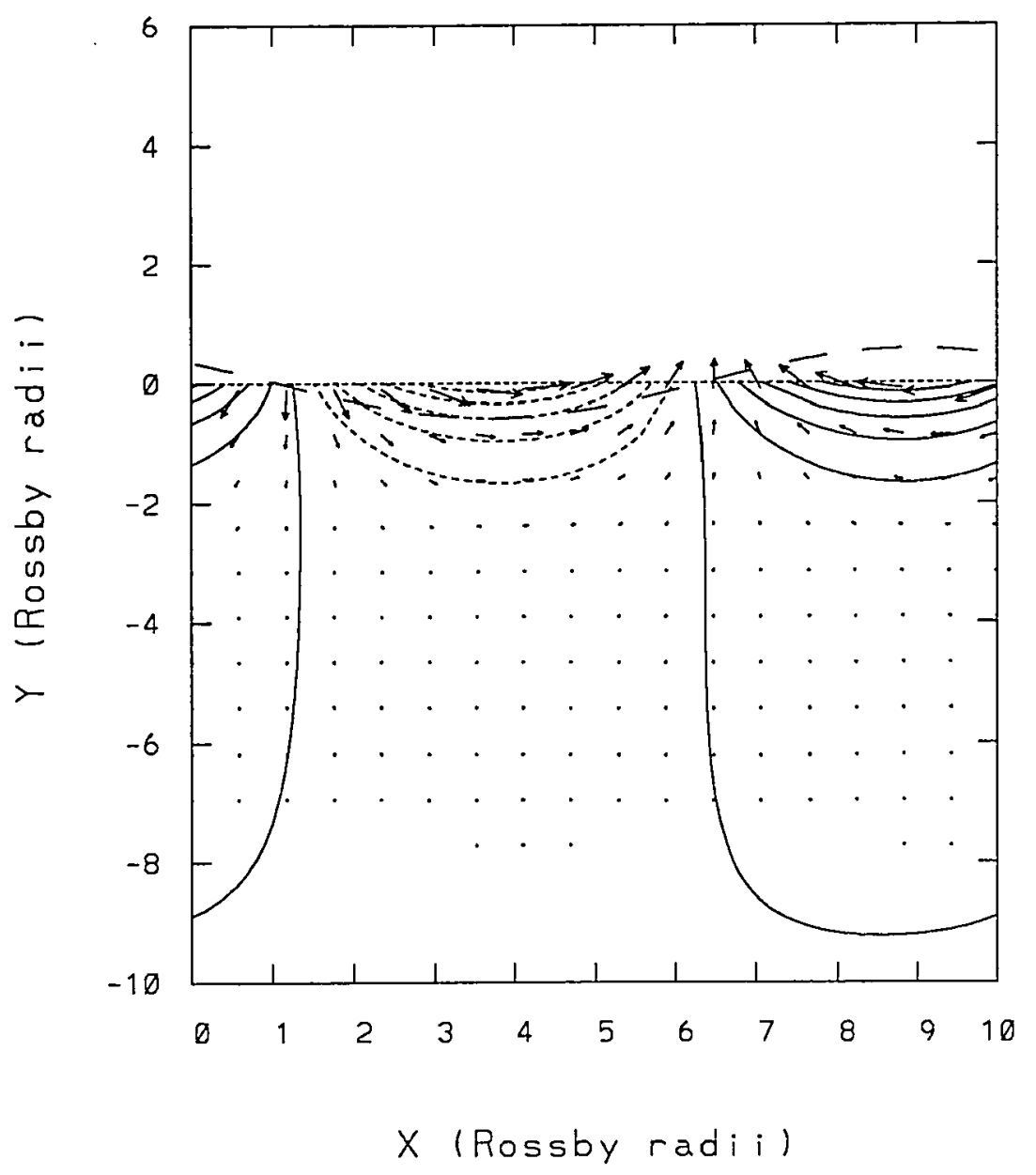


(b)

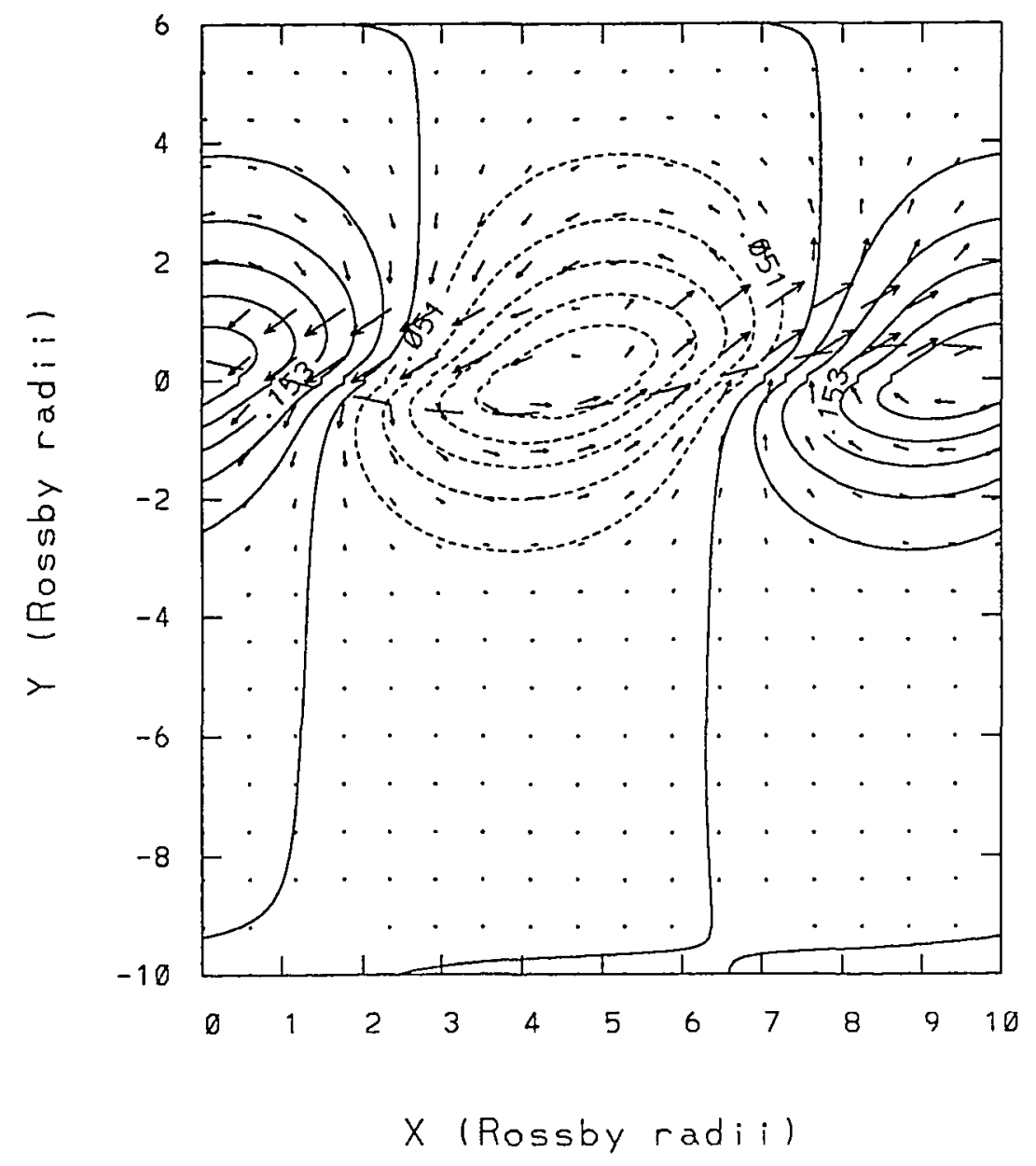


(c)

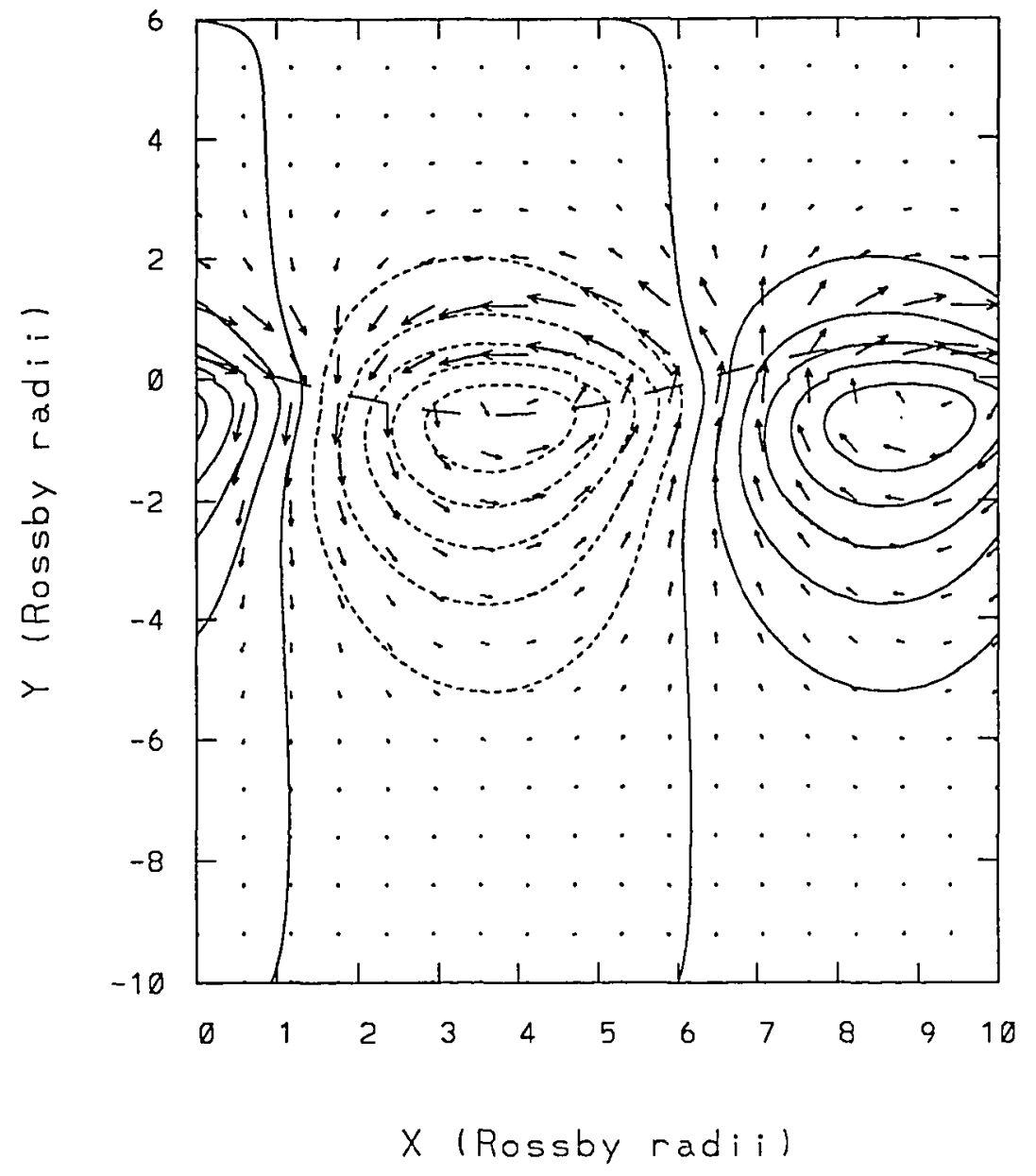


Figure 12: Growth rate of the fastest growing wave as a function of along front wave number $\kappa$, for $H_{0}=2,3$ and 4 . 


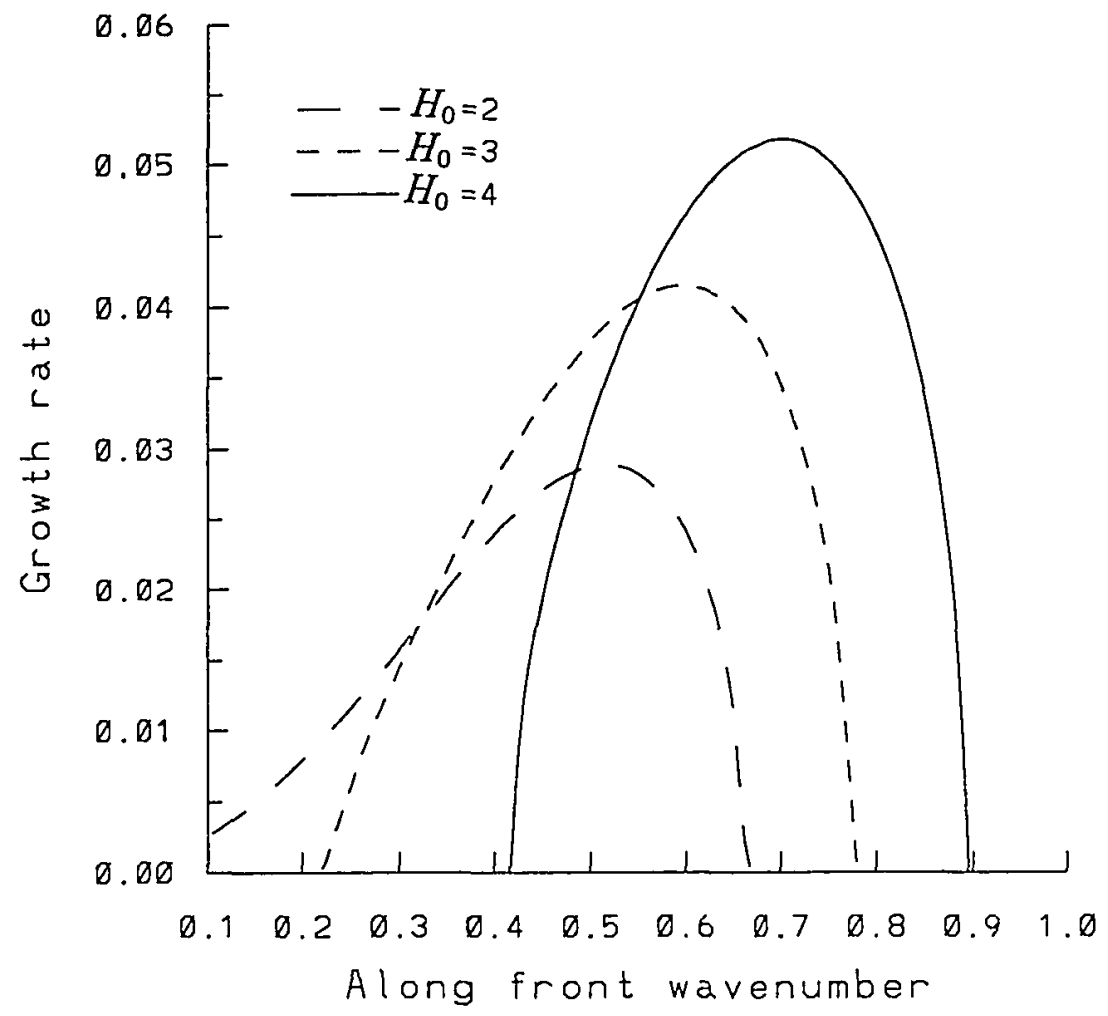


Figure 13: Coastal front, sloping bottom: A time series of total flow in the thermocline layer for one period: (a) $\mathrm{T}=1 / 4$ period, $\mathrm{CI}=0.14$, $\max$ vector $=0.3$; (b) $\mathrm{T}=2 / 4$ period, $\mathrm{CI}=0.14$, $\max$ vector $=0.34$; (c) $\mathrm{T}=3 / 4$ period, $\mathrm{CI}=0.14$, $\max$ vector $=0.50$, dashed lines show the evolution of perturbed front $y_{f}$. 


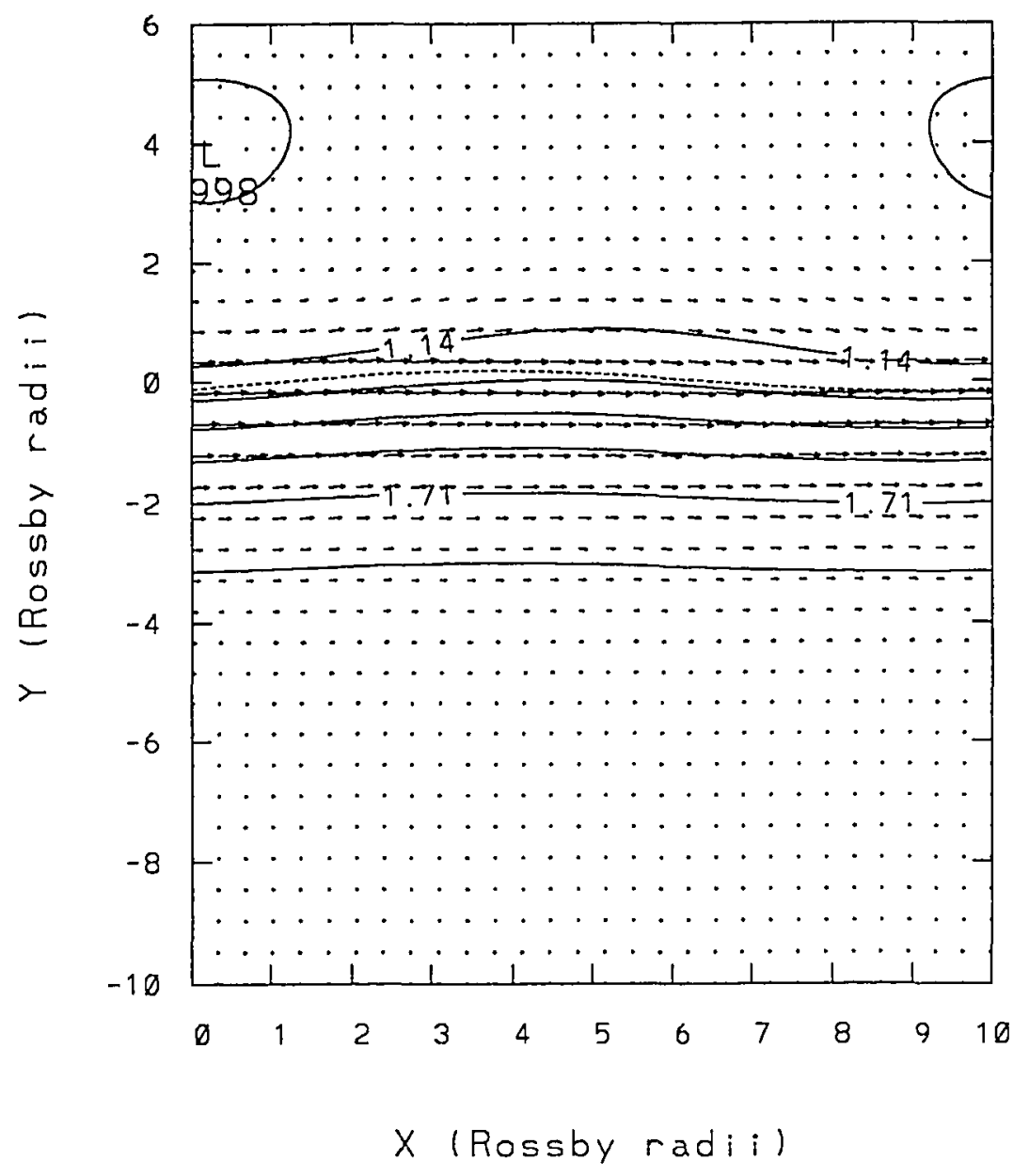




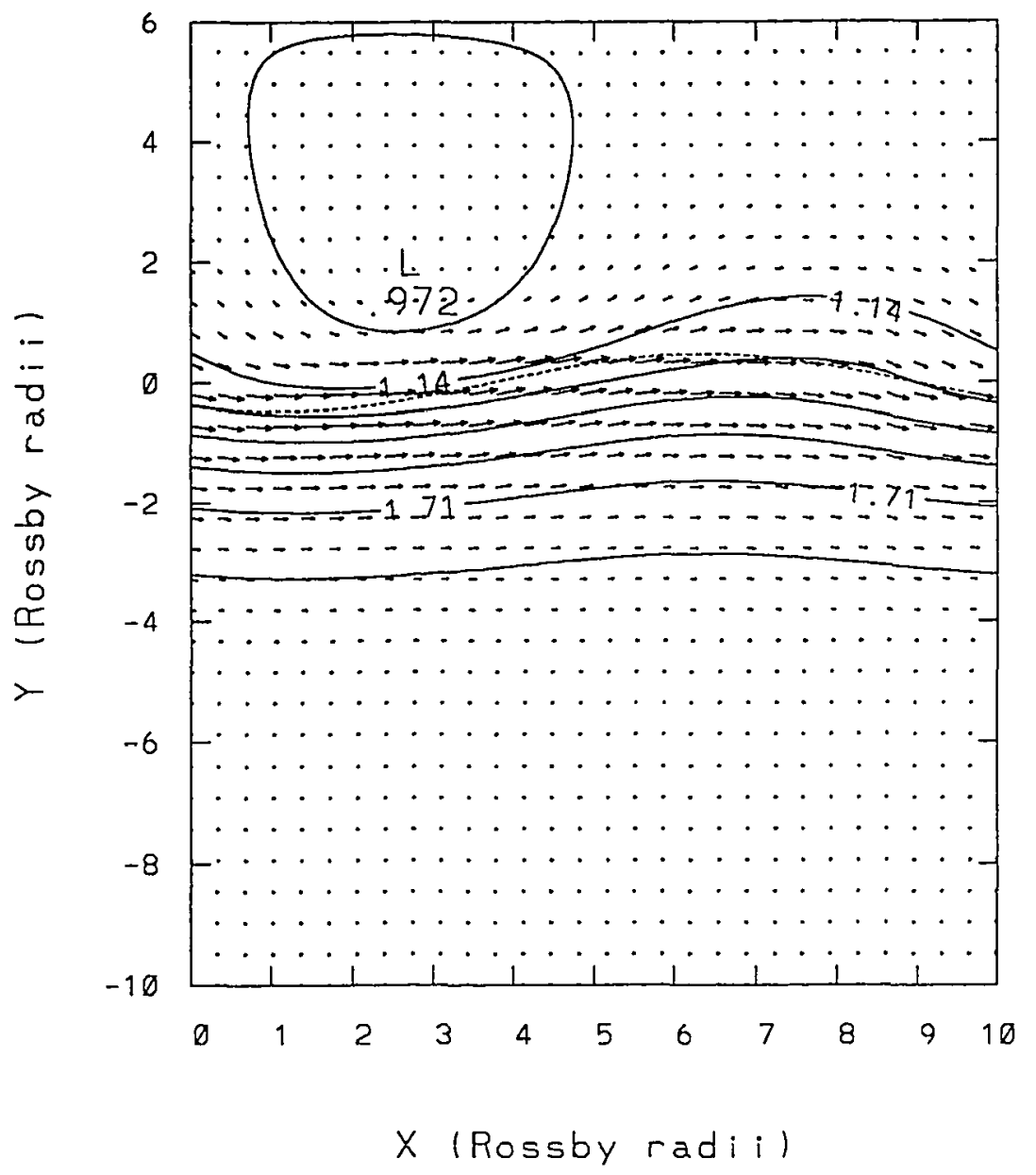




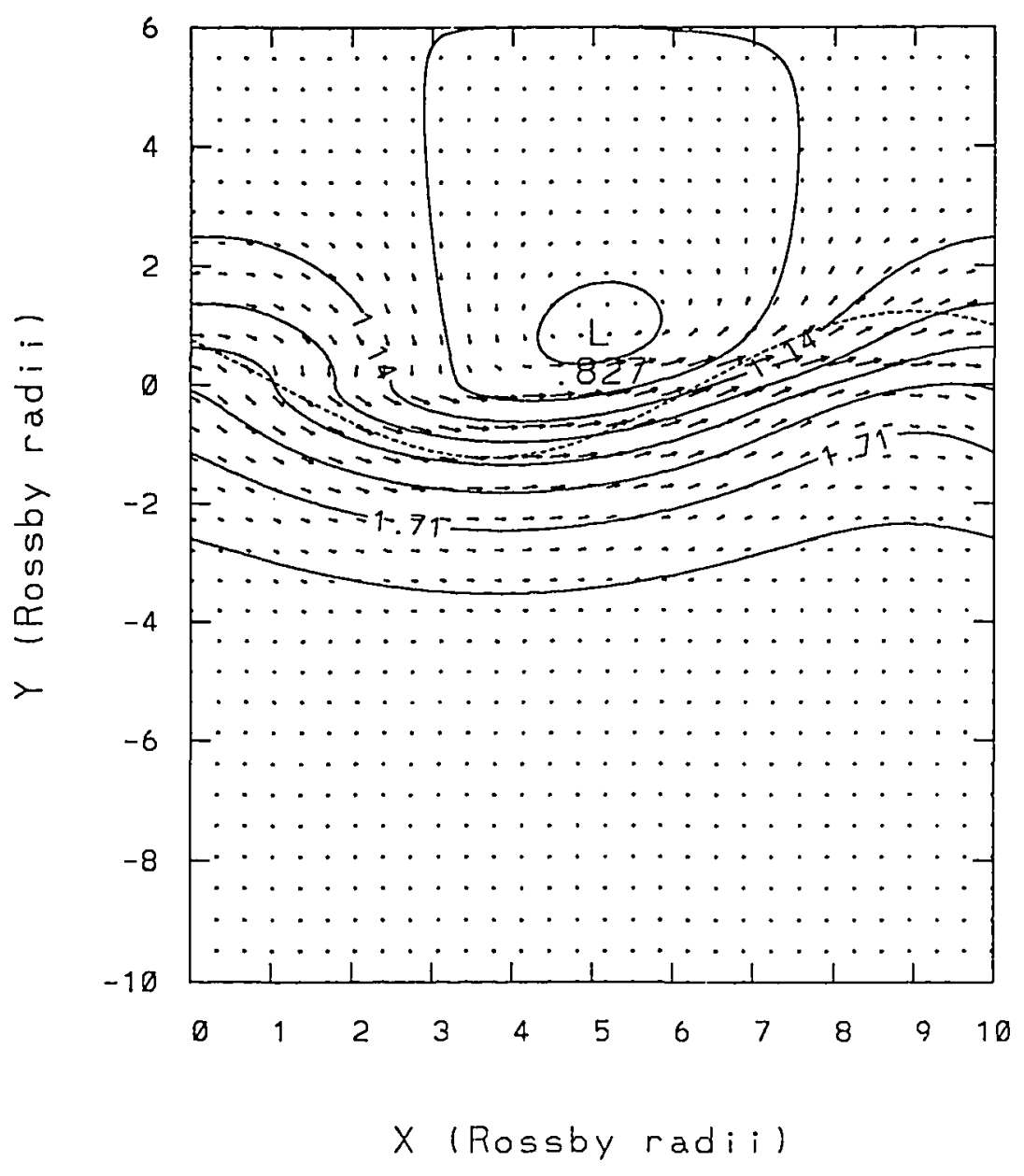




\section{Particle Motions in Unstable Wave Fields}

Recently, several observational studies have been carried out on cross-frontal exchange processes in the Gulf Stream [e.g. Bower and Rossby, 1989; Shaw and Rossby, 1984]. Bower and Rossby [1989] have shown a strong dependence of cross-frontal exchange processes on the time evolution of Gulf Stream meanders, driven by eddycurrent interactions. Their RAFOS drifters on the $27.0 \sigma_{t}$ density surface (equivalent to the thermocline layer in this model) were found to be downwelled (upwelled) and moved offshore (onshore) as the drifters approached cyclonic (anticyclonic) meander troughs (crests).

The trajectories of particles in two-dimensional model wave flows have been investigated theoretically by Flierl [1981] and Garvine [1988]. The results indicate that the pathway of a particle is quite sensitive to initial particle position and also to the phase speed relative to the Eulerian flow velocity. The Eulerian velocity, in the present study, grows with time so that the prediction of the particle motion is far more difficult than in stable linear wave cases.

The pathway of particles inside the thermocline layer was calculated using the Eulerian velocity profiles of the most unstable wave derived from the linear instability model. The position of a particle of fluid located initially at $\vec{x}\left(x_{0}, y_{0}, t_{0}\right)$ after a time $t$ is given by

$$
\vec{x}\left(x_{t}, y_{t}, t\right)=\vec{x}\left(x_{0}, y_{0}, t_{0}\right)+\int_{t_{0}}^{t} \vec{u}\left(x_{0}, y_{0}, t^{\prime}\right) d t^{\prime}
$$

The initial perturbation velocity is assumed to be $1 \%$ of the basic flow. The percentage increases exponentially in time wit $]_{1}$ an e-folding time scale of $1 / w_{i}$, because the wave 
is unstable.

The test case has a wavenumber $(\kappa)$ of 0.6 (non-dimensionalized by $1 / R_{d}$ ), a growth rate $\left(\omega_{i}\right)$ of 0.0415 (non-dimensionalized by $f$ ) and a coast located six Rossby radii apart from the front. The hyperbolic tangent function is used for the bottom topography as in (82). The calculation is carried out until the amplitude of the perturbation velocity becomes $100 \%$ of the basic flow. The results are shown in Fig.14.

The objective of this experiment is not to locate the exact position of trajectories but to get a rough picture how the unstable wave affects the movement of passive drifters in the thermocline layer. The results seem to show cross-front excursion patterns reminiscent of the Bower and Rossby's observation. Particle drift is found to be very sensitive to the initial position of the trajectory. The trajectories inside one or two Rossby radii from the front are observed to be trapped first but eventually move shoreward across the model Gulf Stream suggesting strong interaction of thermocline water with waters near the coast. 
Figure 14: Trajectories of particles in the thermocline layer initially located at the point ' $S$ '. An ' $E$ ' sign indicates the ending point. A ' + ' sign is placed at each time step. 


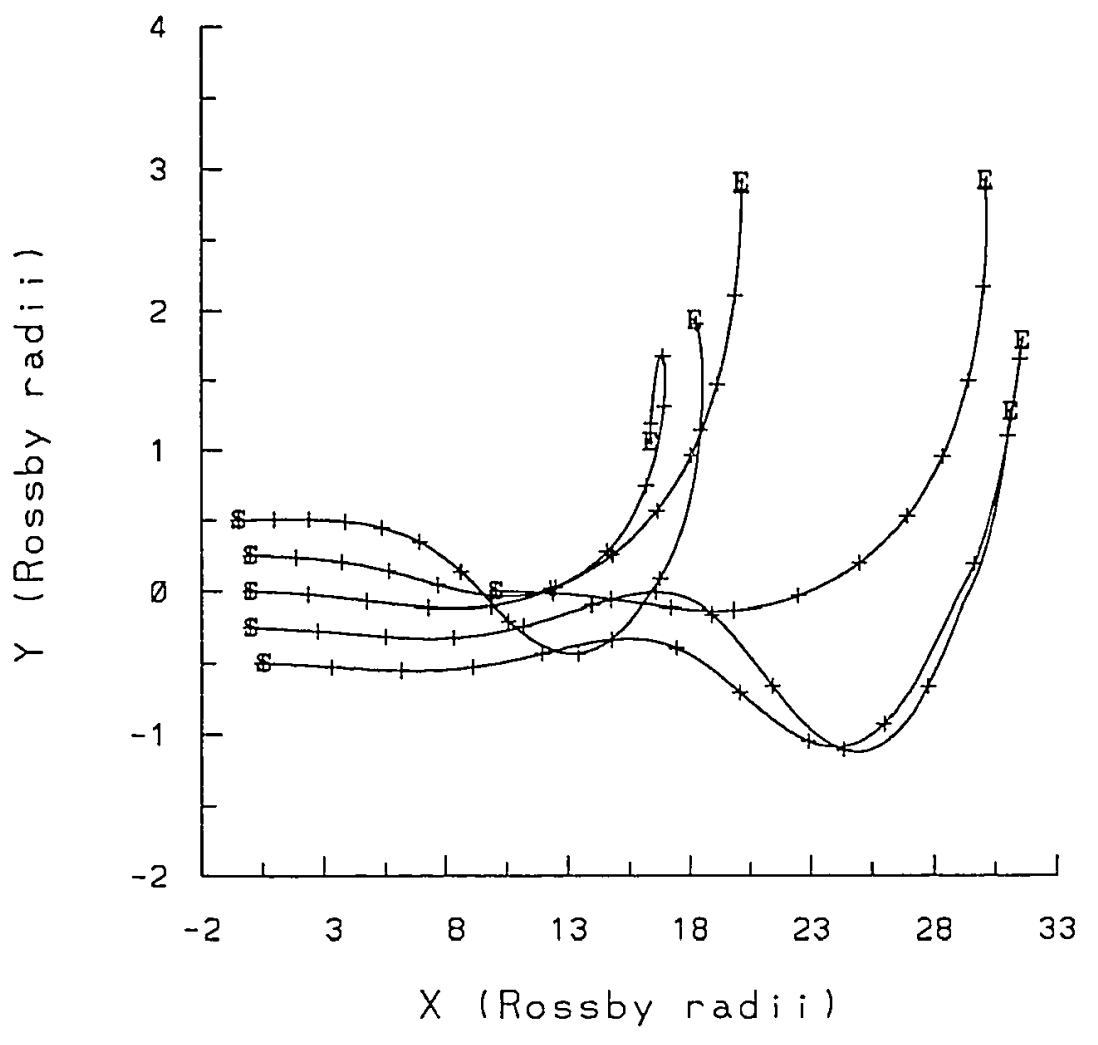




\section{$9 \quad$ Energy Considerations}

Geostrophic fronts, particularly those associated with the western boundary currents, have been long recognized as huge reservoirs of potential energy. Theoretical studies have shown that the geostrophic flows have available kinetic energy to available potential energy of approximately 1:3 [Gill, 1982; Ou, 1986; Van Heijst, 1985]. According to theory, this kind of front is prone to baroclinic instability. In addition, the front is usually accompanied by large horizontal velocity shear which may be the energy source for barotropic instability. Therefore, both energy transformation mechanisms may be simultaneously present in a geostrophic front [Fedorov, 1986]. Here we calculate energy transformations in our model to determine the primary source of energy for the unstable waves.

\subsection{Wave Energy Equations}

The wave energy equation can be obtained directly from the linearized governing equations (see Appendix). The equations for the wave energies integrated over the entire domain (one wavelength in $x$, from $-\infty$ to $+\infty$ for the isolated front and from $-\infty$ to $y_{c}$ for the coastal front in $y$ direction) are

$$
\begin{gathered}
\frac{\partial K_{w}}{\partial t}=\frac{\partial}{\partial t} \int_{s}\left[\bar{h}_{1} \frac{\left(\hat{u}_{1}^{2}+\hat{v}_{1}^{2}\right)}{2}+\delta \bar{h}_{2} \frac{\left(\hat{u}_{2}^{2}+\hat{v}_{2}^{2}\right)}{2}+\bar{h}_{3} \frac{\left(\hat{u}_{3}^{2}+\hat{v}_{3}^{2}\right)}{2}\right] d s \\
=-C\left(K_{w}^{\prime} \rightarrow K_{m}\right)-C\left(K_{w} \rightarrow P_{w}\right), \\
\frac{\partial P_{w}}{\partial t}=\frac{\partial}{\partial t} \int_{s}\left[(1+\alpha) \frac{\hat{h}_{1}^{2}}{2}+\alpha \delta^{2} \frac{\hat{h}_{2}^{2}}{2}+\alpha \delta \hat{h}_{1} \hat{h}_{2}\right] \\
=-C\left(P_{w} \rightarrow P_{m}\right)-C\left(K_{w} \rightarrow P_{w}\right),
\end{gathered}
$$


where $K_{w}$ and $P_{w}$ are wave kinetic and potential energy respectively, $C\left(K_{w} \rightarrow K_{m}\right)$, $C\left(K_{w} \rightarrow P_{w}\right)$ and $C\left(P_{w} \rightarrow P_{m}\right)$ are transfer rates given by

$$
\begin{gathered}
C\left(K_{w} \rightarrow K_{m}\right)=\int_{s}\left[\bar{h}_{1} \frac{d \bar{u}_{1}}{d y} \hat{u}_{1} \hat{v}_{1}+\delta \bar{h}_{2} \frac{d \bar{u}_{2}}{d y} \hat{u}_{2} \hat{v}_{2}\right] d s \\
C\left(K_{w} \rightarrow P_{w}\right)=\int_{s}\left[\bar{h}_{1}\left(\hat{u}_{1} \frac{\partial \hat{p}_{1}}{\partial x}+\hat{v}_{1} \frac{\partial \hat{p}_{1}}{\partial y}\right)+\delta \bar{h}_{2}\left(\hat{u}_{2} \frac{\partial \hat{p}_{2}}{\partial x}+\hat{v}_{2} \frac{\partial \hat{p}_{2}}{\partial y}\right)\right. \\
\left.+\bar{h}_{3}\left(\hat{u}_{3} \frac{\partial \hat{p}_{3}}{\partial x}+\hat{v}_{3} \frac{\partial \hat{p}_{3}}{\partial y}\right)\right] d s \\
C\left(P_{w} \rightarrow P_{m}\right)=\int_{s}\left[\bar{u}_{1} \hat{p}_{1} \frac{\partial \hat{h}_{1}}{\partial x}+\delta \bar{u}_{2} \hat{p}_{2} \frac{\partial \hat{h}_{2}}{\partial x}\right] d s .
\end{gathered}
$$

Adding (84) and (85), we obtain the wave energy equation:

$$
\frac{\partial}{\partial t}\left(K_{w}+P_{w}\right)=-C\left(P_{w} \rightarrow P_{m}\right)-C\left(K_{w} \rightarrow K_{m}\right) .
$$

As usual, $-C\left(P_{w} \rightarrow P_{m}\right)$ represents the energy conversion rate from mean potential energy to perturbation potential energy (the signature of baroclinic instability) and $-C\left(K_{w} \rightarrow K_{m}\right)$ from mean kinetic energy to perturbation kinetic energy (the hallmark of barotropic instability). Another characteristic of barotropic instability is that the phase of the wave velocity leans against the basic horizontal shear [Pedlosky, 1987].

Using $[(6)-(10)],(88)$ can be rewritten as

$$
C\left(P_{m} \rightarrow P_{w}\right)=\int_{s}\left(\bar{u}_{1}-\bar{u}_{2}\right)\left[\hat{p}_{1} \frac{\partial \hat{p}_{2}}{\partial x}\right] d s+\int_{s} \frac{1}{\alpha} \bar{u}_{2}\left[\hat{p}_{2} \frac{\partial \hat{p}_{3}}{\partial x}\right] d s .
$$

If $\hat{p}_{1}, \hat{p}_{2}$ and $\hat{p}_{3}$ are exactly in the same phase, $C\left(P_{m} \rightarrow P_{w v}\right)$ vanishes. Therefore (90) expresses the baroclinic energy conversion mechanism through the phase lag of the perturbation pressures. Equation (88) can also be rewritten as

$$
C\left(P_{m} \rightarrow P_{u}\right)=\int_{s} \bar{u}_{1}\left[\hat{v}_{g 1} \hat{h}_{1}\right] d s+\int_{s} \delta \bar{u}_{2}\left[\hat{v}_{g^{2}} \hat{h}_{2}\right] d s
$$

where subscript $g$ represents the geostrophic part. From this, it is clear that the mean velocities $\left(\bar{u}_{1}, \bar{u}_{2}\right)$ and the geostrophic portion of cross-frontal perturbation volume transport $\left(\hat{v}_{g 1} \hat{h}_{1}, \hat{v}_{g 2} \hat{h}_{2}\right)$ should always be positively correlated in order for the energy to be transferred from mean to wave potential energy through baroclinic instability. 


\subsection{Application to the Isolated Front.}

Since the basic flow isopycnal surface are tilted only in the cross-frontal direction, the relative motion (or phase lag) in the cross-frontal direction between layers is a signature of an unstable wave extracting energy from the basic state potential energy via baroclinic instability. This feature can be seen clearly in the two-dimensional illustrations shown in Fig.5. The solid and dashed curves represent contours of $\hat{p}_{1}, \hat{p}_{2}$ and $\hat{p}_{3}$. The phases in the upper two layers in Fig.5, show that the perturbations are leaning against the basic frontal jet, a sign of barotropic instability: the Reynold stress of the perturbation field reduces the horizontal gradient of the basic frontal jet, resulting in energy conversion from basic to perturbation kinetic energy. The calculated conversion terms $C\left(K_{m} \rightarrow K_{w}\right), C\left(P_{m} \rightarrow P_{w}\right)$, are plotted in Fig.15 for the isolated front. It is seen that $C\left(K_{m} \rightarrow K_{w}\right)$ is about $32.0 \%$ of $C\left(P_{m} \rightarrow P_{w}\right)$ and positive. This shows that the unstable wave draws energy mainly from the mean potential energy, and kinetic energy transfer is from mean flow to perturbation, not vice versa. Of the total transfer $C\left(K_{m} \rightarrow K_{w}\right)$ plus $C\left(P_{m} \rightarrow P_{w}\right)$, about $75 \%$ is from mean flow potertial energy, the rest from mean flow's kinetic energy. Magnitudes shown are not important since the amplitude of the perturbations is arbitrary.

\subsection{Application to the Coastal Front}

The energy conversion terms $C\left(K_{m} \rightarrow K_{w}\right), C\left(P_{m} \rightarrow P_{w}\right)$ are plotted in Fig.16 for the flat bottom model. The calculation shows that $C\left(K_{m} \rightarrow K_{w}\right)$ is about $32.4 \%$ of $C\left(P_{m} \rightarrow P_{w}\right)$, much the same as for the isolated front.

When bottom topography is included in the model, the energy conversion terms $C\left(K_{m} \rightarrow K_{w}\right), C\left(P_{m} \rightarrow P_{w}\right)$ change, see Fig.17. In that, case, $C\left(K_{m} \rightarrow K_{w}^{\prime}\right)$ is only about $19 \%$ of $C\left(P_{m} \rightarrow P_{w}\right)$ and the sign is negative in the three-layer region. In other 
Figure 15: Isolated front: (a) Energy conversion rate term $C\left(K_{m} \rightarrow K_{w}\right)$, (b) Energy conversion rate term $C\left(P_{m} \rightarrow P_{w}\right)$. 
(a)
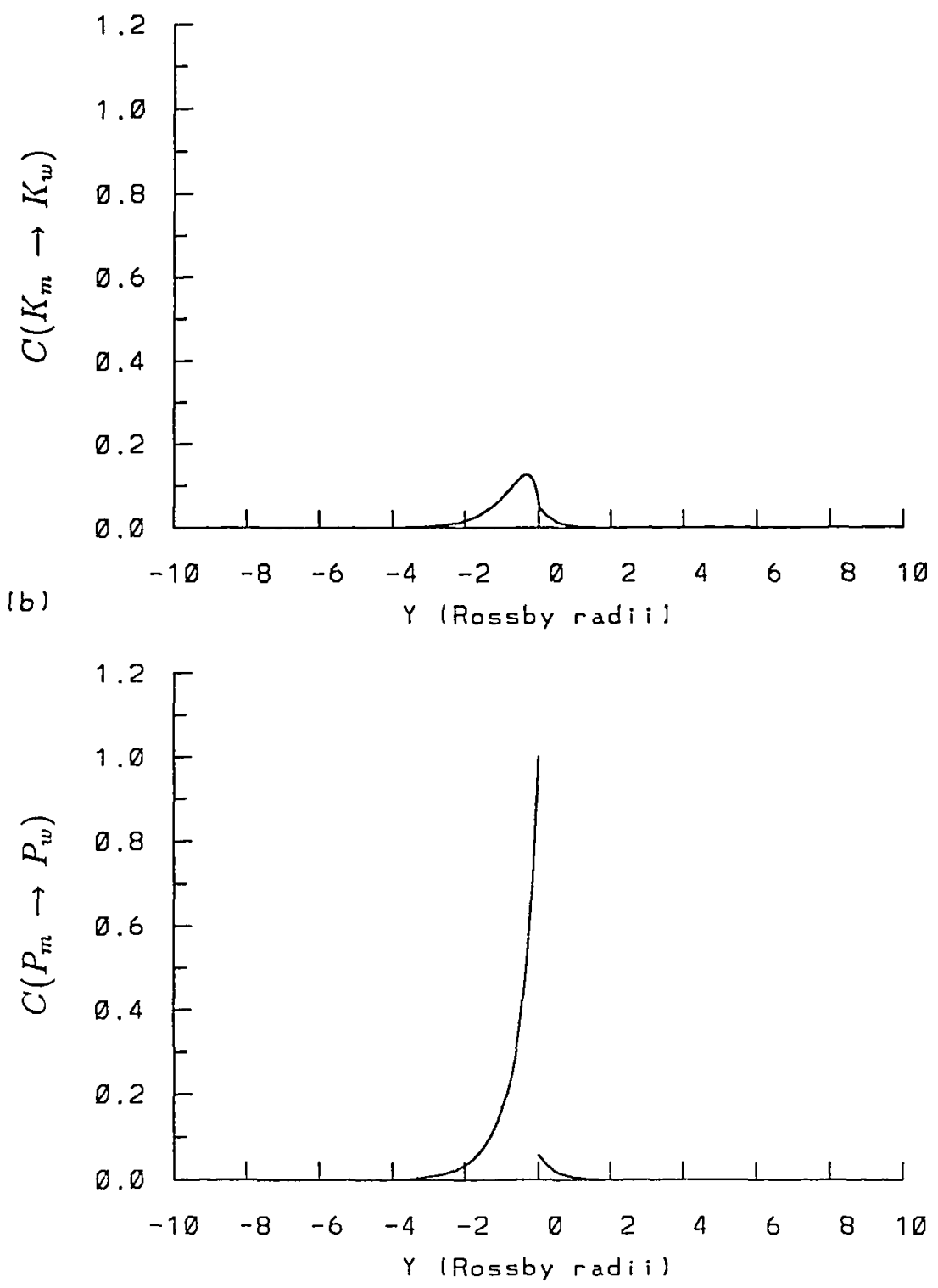
Figure 16: Coastal front, flat bottom: (a) Energy conversion rate term $C\left(K_{m} \rightarrow K_{w}\right)$, (b) Energy conversion rate term $C\left(P_{m} \rightarrow P_{w}\right)$. 
(a)
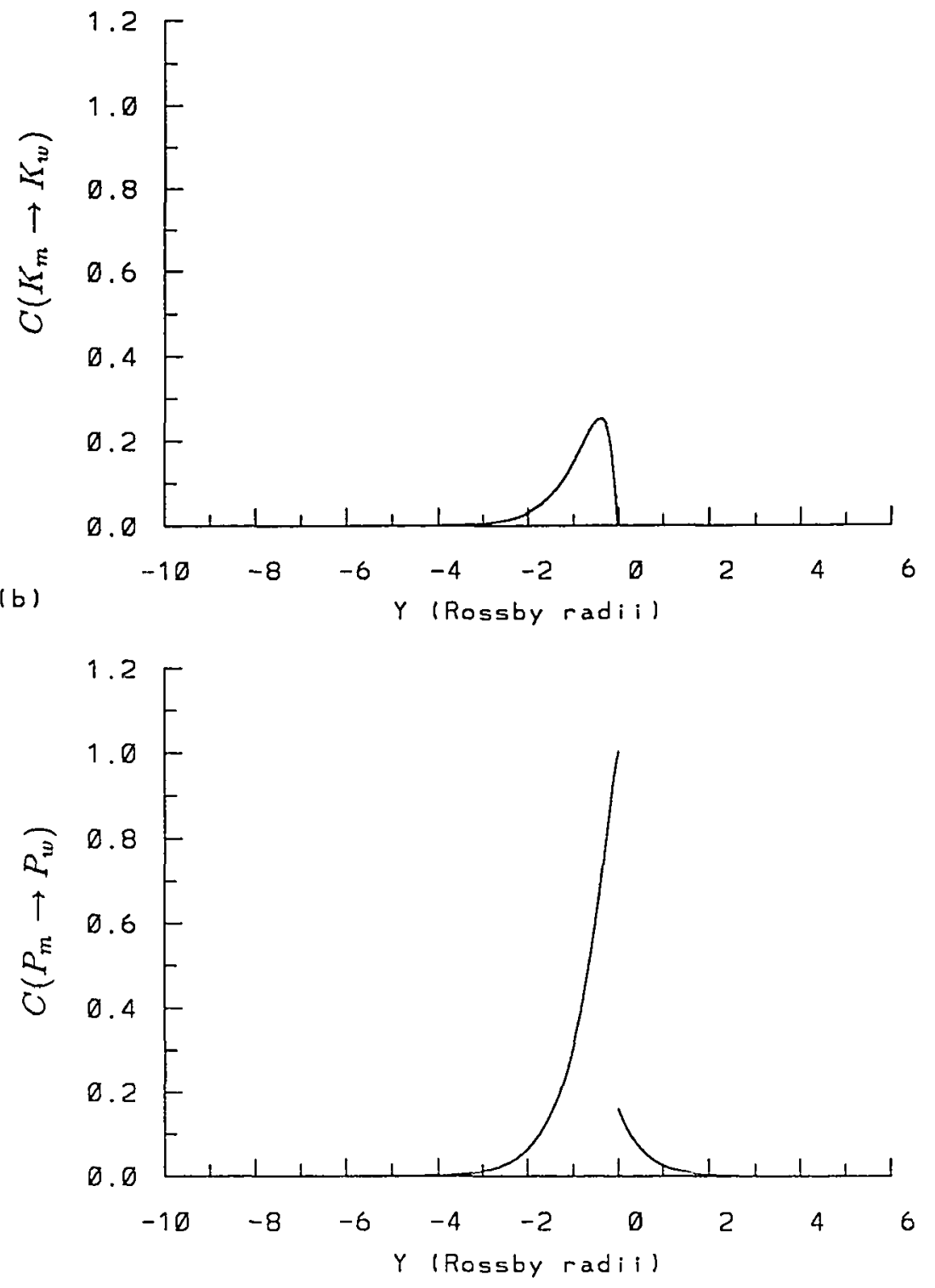
Figure 17: Coastal front, sloping bottom: (a) Energy conversion rate term $C\left(K_{m} \rightarrow\right.$ $\left.K_{w}\right)$, (b) Energy conversion rate term $C\left(P_{m} \rightarrow P_{w}\right)$. 
(a)
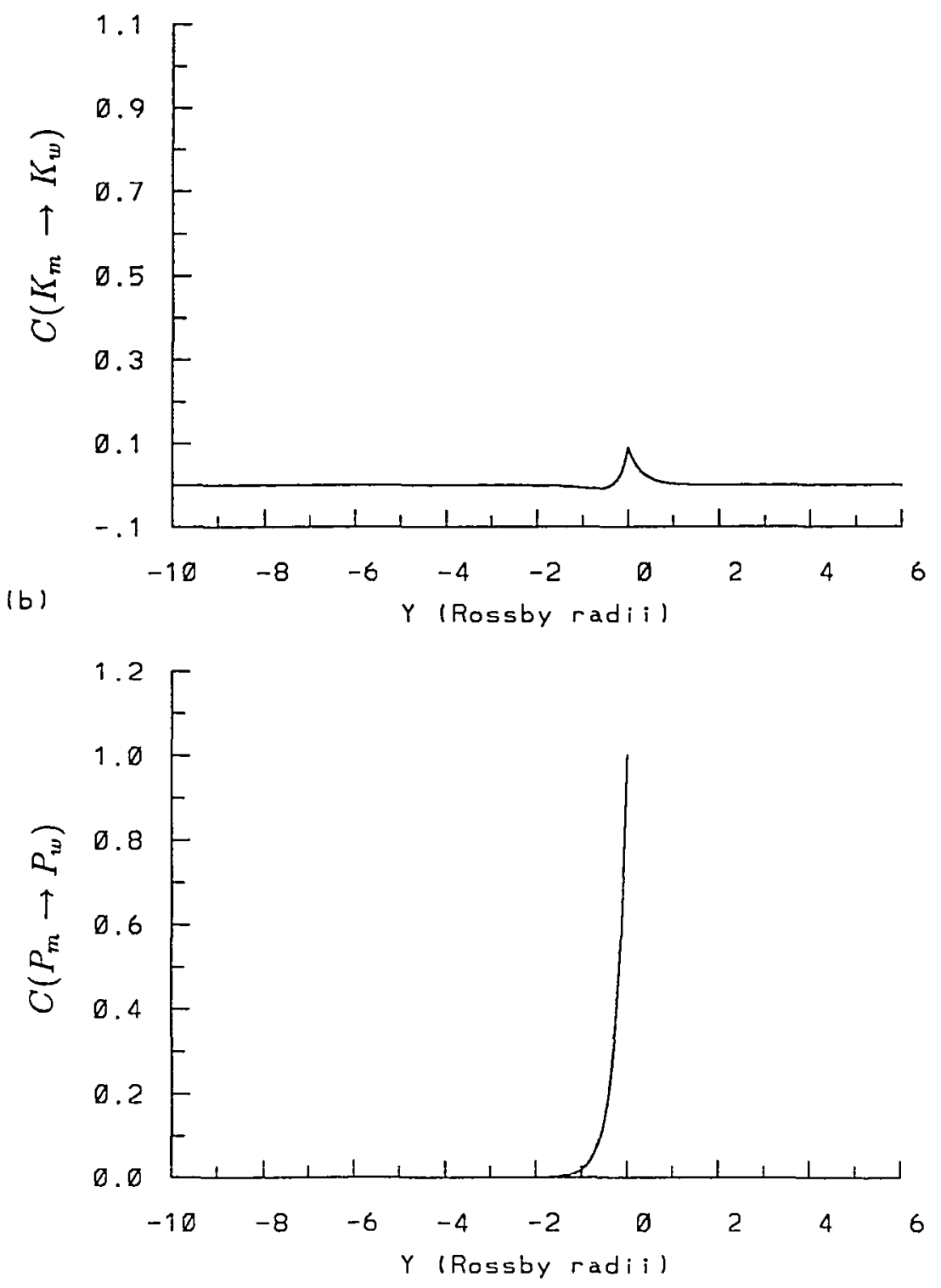
words, the unstable wave draws energy from mean potential energy and some portion of that energy is transferred back to mean kinetic energy in the three-layer region via "negative viscosity". 


\section{Conclusions}

The primary objective of this study was to gain insight into the behavior of the thermocline layer. The eigenfunctions of the most unstable wave show a cyclonic thermocline eddy underlying the trough of a meander, an anticyclonic eddy the crest. Putting mean flow and perturbation together, a large cyclonic eddy (some $200 \mathrm{~km}$ diameter) develops in slopewater, shoreward of a meander trough. The dominant feature of calculated particle trajectories in the thermocline layer is ejection into slopewater. Of course linear instability calculations can only suggest tendencies in the finite amplitude development of geostrophic turbulence. Nevertheless, the large range of unstable thermocline eddy motion strongly suggests vigorous exchange between slopewater and the Gulf Stream thermocline, as inferred from observation (Csanady and Hamilton, 1988). The large cyclonic eddy in a meander trough offers a further explanation for the observed acceleration of the upper slope current in the MidAtlantic Bight at the time of Gulf Stream approaches to the coast: the acceleration occurs half a wavelength to the east of a meander crest, bringing Gulf Stream close to the coast.

On the more conventional topic of Gulf Stream instability, our three layer model revealed unstable ageostrophic perturbations of fairly long wavelength. For parameters, typical of the Gulf Stream west of $70^{\circ} \mathrm{W}$, the most unstable wave was found to propagate slowly in the downstream direction with a phase speed of $19-33.7 \mathrm{~cm} / \mathrm{sec}$, an e-folding time scale of $2.8-6.3$ days and a wavelength of $314-438 \mathrm{~km}$. Typically, the waves had frequencies much below the inertial frequency (subinertial) and 
phase speed slow compared to the mean current speed. Nevertheless, the shape of the eigenfunctions showed the unstable wave to be ageostrophic. The model results agree well with observations of Watts et al., [1982] downstream of Cape Hatteras.

Calculations of energy conversion rates revealed that the unstable waves found near the surface front were mainly a result of baroclinic instability and the effect of horizontal shear is relatively small. When a hyperbolic-tangent shaped coastal slope was included in the model, the influence of horizontal Reynolds stress remained unimportant in the energy balance of the perturbations. In contrast to calculations of Orlanski [1969], the present study showed horizontal Reynolds stress always extracting energy from the mean flow. The difference is presumably due to the different basic flows chosen. Orlanski chose a basic flow of highly dissipative character near the front [e.g. Garvine, 1983]. The maximum of the basic flow occurred far offshore from the front. This changed the sign of the basic horizontal shear near the front.

Regarding the effect of an active thermocline layer on the unstable waves, the growth rate was found to be slightly less, the wavelength of the most unstable wave was much greater than for the two-layer case. An active thermocline layer thus slightly stabilizes the front and shifts the instability to lower wavenumber. Reduced vertical shear (compared to the two-layer model) seems to be responsible for this stabilization. We also found that the width of the two-layer region limited by a coast stabilizes the front, when it drops below an internal deformation radius, a result previously obtained by Oey [1988]. Bottom topography (of hyperbolic-tangent shape) destabilizes the front.

Calculated particle trajectories showed them to be very sensitive to the initial location of the particle. The trajectories inside one or two Rossby radii from the front were trapped for a while, later moved across the front, shoreward. 


\section{Appendix}

\section{Wave energy equations}

The wave energy equation can be obtained directly from the linearized governing equations:

$$
\begin{gathered}
\frac{\partial \hat{u}_{j}}{\partial t}+\bar{u}_{j} \frac{\partial \hat{u}_{j}}{\partial x}+\left(\bar{u}_{j y}-1\right) \hat{v}_{j}=-\frac{\partial \hat{p}_{j}}{\partial x}, \\
\frac{\partial \hat{v}_{j}}{\partial t}+\bar{v}_{j} \frac{\partial \hat{u}_{j}}{\partial x}+\hat{u}_{j}=-\frac{\partial \hat{p}_{j}}{\partial y} \\
\frac{\partial \hat{h}_{j}}{\partial t}+\frac{\partial}{\partial x}\left(\bar{u}_{j} \hat{h}_{j}+\hat{u}_{j} \bar{h}_{j}\right)+\frac{\partial}{\partial y}\left(\hat{v}_{j} \bar{h}_{j}\right)=0
\end{gathered}
$$

where $j=1,2$, overbar and hat denote basic and perturbation terms respectively. For the bottom layer, the linearized governing equations are

$$
\begin{gathered}
\frac{\partial \hat{u}_{3}}{\partial t}-\hat{v}_{3}=-\frac{\partial \hat{p}_{3}}{\partial x} \\
\frac{\partial \hat{v}_{3}}{\partial t}+\hat{u}_{3}=-\frac{\partial \hat{p}_{3}}{\partial y} \\
\frac{\partial \hat{h}_{3}}{\partial t}+\frac{\partial}{\partial x}\left(\hat{u}_{3} \bar{h}_{3}\right)+\frac{\partial}{\partial y}\left(\hat{v}_{3} \bar{h}_{3}\right)=0
\end{gathered}
$$

Multiplying the $x$ momentum equations (A1) and (A4) by $\bar{h}_{j} \hat{u}_{j}, y$ momentum equations (A2) and (A5) by $\bar{h}_{j} \hat{v}_{j}$ where $j=1,2,3$, and again multiplying $\delta$ to those equations for $j=2$, then integrating over the entire domain (one wavelength in $x$, from $-\infty$ to $+\infty$ for the isolated front and from $-\infty$ to $y_{c}$ for the coastal front in $y$ direction), we obtain the equation for the wave kinetic energy $K_{u}$ :

$$
\begin{array}{r}
\frac{\partial K_{w}}{\partial t}=\frac{\partial}{\partial t} \int_{s}\left[\bar{h}_{1} \frac{\left(\hat{u}_{1}^{2}+\hat{v}_{1}^{2}\right)}{2}+\delta \bar{h}_{2} \frac{\left(\hat{u}_{2}^{2}+\hat{v}_{2}^{2}\right)}{2}+\bar{h}_{3} \frac{\left(\hat{u}_{3}^{2}+\hat{v}_{3}^{2}\right)}{2}\right] d s \\
=-C\left(K_{w} \rightarrow K_{m}\right)-C\left(K_{w} \rightarrow P_{w}\right)
\end{array}
$$


where $C\left(K_{w} \rightarrow K_{m}\right)$ and $C\left(K_{w} \rightarrow P_{w}\right)$ are given as

$$
\begin{gathered}
C\left(K_{w} \rightarrow K_{m}\right)=\int_{s}\left[\bar{h}_{1} \frac{d \bar{u}_{1}}{d y} \hat{u}_{1} \hat{v}_{1}+\delta \bar{h}_{2} \frac{d \bar{u}_{2}}{d y} \hat{u}_{2} \hat{v}_{2}\right] d s \\
C\left(K_{w} \rightarrow P_{w}\right)=\int_{s}\left[\bar{h}_{1}\left(\hat{u}_{1} \frac{\partial \hat{p}_{1}}{\partial x}+\hat{v}_{1} \frac{\partial \hat{p}_{1}}{\partial y}\right)+\delta \bar{h}_{2}\left(\hat{u}_{2} \frac{\partial \hat{p}_{2}}{\partial x}+\hat{v}_{2} \frac{\partial \hat{p}_{2}}{\partial y}\right)\right. \\
\left.+\bar{h}_{3}\left(\hat{u}_{3} \frac{\partial \hat{p}_{3}}{\partial x}+\hat{v}_{3} \frac{\partial \hat{p}_{3}}{\partial y}\right)\right] d s .
\end{gathered}
$$

To obtain the equation for wave potential energy $P_{w}$, we multiply the continuity equations (A3) and (A6) by $\hat{p}_{j}$ and then again multiply $\delta$ to those equations for $j=2$. Integrating it over the domain, we get

$$
\begin{array}{r}
\frac{\partial P_{u}}{\partial t}=\frac{\partial}{\partial t} \int_{s}\left[(1+\alpha) \frac{\hat{h}_{1}^{2}}{2}+\alpha \delta^{2} \frac{\hat{h}_{2}^{2}}{2}+\alpha \delta \hat{h}_{1} \hat{h}_{2}\right] \\
=-C\left(P_{u} \rightarrow P_{m}\right)-C\left(K_{u} \rightarrow P_{u}\right)
\end{array}
$$

where $C\left(P_{w} \rightarrow P_{m}\right)$ can be written as

$$
C\left(P_{w} \rightarrow P_{m}\right)=\int_{s}\left[\hat{p}_{1} \bar{u}_{1} \frac{\partial \hat{h}_{1}}{\partial x}+\delta \hat{p}_{2} \bar{u}_{2} \frac{\partial \hat{h}_{2}}{\partial x}\right] d s .
$$

Adding (A7) and (A10), we get the wave energy equation:

$$
\frac{\partial}{\partial t}\left(K_{w}+P_{w}\right)=-C\left(P_{u} \rightarrow P_{m}\right)-C\left(K_{w} \rightarrow K_{m}^{\prime}\right)
$$




\section{Bibliography}

Atkinson, L. P., T. N. Lee, J.O. Blanton, and G.A. Paffenhofer. 1987. Summer upwelling on the southeastern continental shelf of the U.S.A. during 1981: Hydrographic observations. Prog. Oceanogr., 19, 231-266.

Bane, J. M., O. B. Brown, R. H. Evans, and P. Hamilton. 1988. Gulf Stream remote forcing of Shelfbreak Currents in the Mid-Atlantic Bight. Geophy. Res. Letters, $15,405-407$.

Barth, J. A. 1987. Stability of a coastal upwelling front over topography. Ph.D. Dissertation, MIT/WHOI-87-48, 187pp.

Bower, A. S., and T. Rossby. 1989. Evidence of cross-frontal exchange processes in the Gulf Stream based on isopycnal RAFOS float data. J. Phys. Oceanogr., 19, 1177-1190.

Brooks, I. H., and P. P. Niiler, 1977. Energetics of the Florida Current. J. Mar. Res., 35, 163-191.

Chia, F., R. W. Griffiths and P. F. Linden. 1982. Laboratory experiments on fronts. Part II: The formation of cyclonic eddies at upwelling fronts. Geophys. Astrophys. Fluid Dyn., 19, 189-206.

Csanady, G. T. 1982. On the structure of transient upwelling events. J. Phys. Oceanogr., 12, 84-96.

Csanady, G. T., and P. Hamilton. 1988. Circulation of Slopewater. Cont. Shelf Res., $8,565-624$.

C'sanady, G. T. 1989. Energy dissipation and upwelling in a western boundary current. J. Phys. Oceanogr., 19, 462-473.

Fedorov, K. N. 1986. The physical nature and structure of oceanic fronts. SpringerVerlag, New York, 333 pp.

Flierl, G. R. 1981. Particle motions in large amplitude wave fields. Geoplyys. Astrophys. Fluid Dyı., 18, 39-74. 
Garvine, R. W. 1983. Stationary waves on oceanic density fronts. Deep-Sea Res., 30, 245-266.

Garvine, R. W. 1988. Flow field properties of long, propagating frontal wave. J. Phys. Oceanogr., 18, 788-792.

Gerald, C. F. and P. O. Wheatly. 1985. Applied Numerical Analysis. Addison-Wesly, Massachusetts, $340 \mathrm{pp}$.

Gill, A. E. 1982. Atmosphere-Ocean Dynamics. Academic Press, New York, 662 pp.

Griffiths, R. W. and P. F. Linden. 1982. Laboratory experiments on fronts. Part I: Density-driven boundary currents. Geophys. Astrophys. Fluid Dyn., 19, 159-187.

Hitchcock, G. L, A. J. Mariano and T. Rossby. 1993. Mesoscale pigment fields in the Gulf Stream: Observations in a meander crest and trough. J. Geophys. Res., 98, 8425-8445.

Huang, R. X. and H. Stommel. 1990. Cross sections of a two-layer inertial Gulf Stream. J. of Phys. Oceanogr., 20, 907-911.

Killworth, P. D. 1983. Long-wave instability of an isolated front. Geophys. Astrophys. Fluid Dyn., 25, 235-258.

Killworth, P. D., N. Paldor and M. E. Stern. 1984. Wave propagation and growth on a surface front in a two-layer geostrophic current. J. Mar. Res., 42, 761-785.

Kroll, J. 1992. The stability of a canonical front. J. Mar. Res., 50, 183-205.

Kubokawa, A. 1985. Instability of a geostrophic front and its energetics. Geophys. Astrophys. Fluid Dyn., 33, 223-257.

Lee, T. N., and L. P. Atkinson. 1983. Low-frequency current and temperature variability from Gulf Stream frontal eddies and atmospheric forcing along the southeast U.S. outer continental shelf. J. Geophys. Res., 88, 4541-4568.

Lee, T. N., J. A. Yoder, and L. P. Atkinson. 1991. Gulf Stream frontal eddy influence on productivity of the southeast U.S. continental shelf. J. Geophys. Res., 96, 22191-22205.

Lohrenz, S. E., J. J. Cullen, D. A. Phinney, D. B. Olson and C. S. Yentsch. 1993. Distributions of pigments and primary production in a Gulf Stream meander. J. Geophys. Res., 98, 14547-14560. 
Oey, L. Y. 1988. A model of Gulf Stream frontal instabilities, meanders and eddies along the continental slope. J. Phys. Oceanogr., 18, 211-229.

Orlanski, I. 1968. Instability of frortal waves. J. Atmos. Sci., 25, 178-200.

Orlanski, I. 1969. The influence of bottom topography on the stability of jets in a baroclinic fluid. J. Atmos. Sci., 26, 1216-1232.

Ou, H. W. 1986. On the energy conversion during geostrophic adjustment. J. Phys. Oceanogr., 16, 2203-2204.

Paffenhofer, G. A., B. K. Sherman, and T. N. Lee. 1987. Summer upwelling on the southeastern continental shelf of the U.S.A. during 1981: Changes in distribution and abundance of particulate matter. Prog. Oceanogr., 19, 373-401.

Paldor, N. 1983. Linear stability and stable modes of geostrophic fronts. Geophys. Astrophys. Fluid Dyn., 24, 299-326.

Pedlosky, J. 1962. Baroclinic instability in two-layer systems. Tellus, 15, 20-25.

Pedlosky, J. 1987. Geophysical Fluid Dynamics. Springer-Verlag, New York, 710 pp.

Phillips, N. A. 1954. Energy transformations and meridional circulations associated with simple baroclinic waves in a two-level, quasi-geostrophic model. Tellus, 11, 273-286.

Schmitz, W. J., Jr., and P. P. Niiler. 1969. A note on the kinetic energy exchange between fluctuations and mean flow in the surface layer of the Florida Current. Tellus, 21, 814-819.

Shaw, P. T. and H. T. Rossby. 1984. Towards a Lagrangian description of the Gulf Stream. J. Phys. Oceanogr., 14, 528-540.

Starr, V. P. 1968. Physics of negative viscosity phenomena. McGraw-Hill, New York, $256 \mathrm{pp}$.

Stommel, H. 1965. The Gulf Stream: A physical and dynamic description. Univ. California Press, 248 pp.

Van Heijst, G. J. F. 1985. A geostrophic adjustment model of a tidal mixing front. J. Phys. Oceanogr., 15, 1182-1190.

Watts, D. R. and W. E. Johns. 1982. Gulf Stream meanders: Observations on propagating and growth. J. Geophys. Res., 8T, 9467-9476. 
Webster, F. 1961. The effect of meander on the kinetic energy balance of the Gulf Stream. Tellus, 13, 392-401. 